\title{
Fischpopulationen unter Stress - das Beispiel des Unteren Neckars
}

\author{
Thomas Braunbeck $\cdot$ Henner Hollert · Annika Brauns $\cdot$ Steffen Keiter · Patrick Schwartz
}

Eingegangen: 24. Dezember 2008/Akzeptiert: 23. Februar 2009/Online veröffentlicht: 19. März 2009

(C) Springer-Verlag 2009

\begin{abstract}
Zusammenfassung Hintergrund und Ziel Berichte über Fischrückgänge bzw. Fischpopulationen mit ungewöhnlicher Populationszusammensetzung in zahlreichen Flusssystemen in Europa und Nordamerika stehen in scharfem Kontrast zu Analysen der Gewässergüte, die für die letzten Jahre eindeutig eine Verbesserung belegen. Als ehemals recht stark kontaminierter Fluss in Süddeutschland erfuhr auch der Neckar über viele Jahre eine kontinuierliche, deutliche Verbesserung seines ökologischen Zustands. Dennoch sind gerade am Unteren Neckar Defizite in den Fischbeständen zu beobachten, die mit konventionellen chemischanalytischen, hydromorphologischen und limnologischen Methoden nicht erklärt werden können. Aus diesem Grund wurden über einen Zeitraum von mehreren Jahren ökotoxikologische Untersuchungen am Unteren Neckar durchgeführt, die sich zunehmend auf Schwebstoffe und Sedimente als Reservoire für Schadstoffe konzentrierten. Parallel zu direkten Untersuchungen zur Toxizität der Sedimente wurden Fische aus dem Unteren Neckar wiederholt hinsichtlich
\end{abstract}

Herrn Prof. Dr. Dr. h. c. Volker Storch zum 65. Geburtstag gewidmet. Herausgeber: Henner Hollert · Thomas Braunbeck

\footnotetext{
T. Braunbeck $(\bowtie) \cdot$ A. Brauns $\cdot$ S. Keiter Aquatische Ökologie und Toxikologie, Institut für Zoologie, Universität Heidelberg, Im Neuenheimer Feld 230, 69120 Heidelberg, Deutschland E-Mail: braunbeck@zoo.uni-heidelberg.de

H. Hollert

Institut für Umweltforschung (Biologie V), Lehr- und Forschungsgebiet Ökosystemanalyse, Rheinisch-Westfälische Technische Hochschule Aachen, Worringerweg 1, 52074 Aachen, Deutschland

P. Schwartz

Universität Basel, Mensch-Gesellschaft-Umwelt (MGU), Vesalgasse 1, 4051 Basel, Schweiz
}

spezifischer Endpunkte wie Gentoxizität, mutagener Veränderungen sowie histo- und cytopathologischer Veränderungen in zentralen Monitororganen untersucht, um Hinweise auf Mechanismen zu finden, die den Defiziten in der $\mathrm{Zu}-$ sammensetzung der Fischpopulationen zugrunde liegen könnten.

Material und Methoden Rotaugen (Rutilus rutilus) und Gründlinge (Gobio gobio) aus dem Unteren Neckar wurden hinsichtlich histo- und cytopathologischer Veränderungen in der Leber sowie der Induktion gentoxischer Effekte in Leber-, Darm-, Kiemen- und Blutzellen mit Hilfe von Comet- und Mikrokern-Assay untersucht. Parallel wurden Sedimente aus Aue-ähnlichen Randbereichen am Unteren Neckar in nativem Zustand sowie nach acetonischer Extraktion auf teratogene Wirkungen im Fischembryotest mit dem Zebrabärbling (Danio rerio) geprüft. Als Ergänzung wurden die Sedimente schließlich hinsichtlich ihrer (cyto-)toxischen Wirkung auf permanente Fischzelllinien untersucht.

Ergebnisse Massive Störungen der Ultrastruktur der Leber zeigen eine starke Stresssituation der Fische im Unteren Neckar (trotz guter Nährstoffversorgung) an. Sowohl Cytoals auch Fischembryotoxizitätstests dokumentieren eine erhebliche Toxizität der Sedimente vom Unteren Neckar, und die Befunde von Comet- und Mikrokernassay belegen nicht nur ein deutliches gentoxisches Belastungspotenzial der Sedimente, sondern auch direkte gentoxische Wirkungen in Fischen. Ein Rückgang der gentoxischen Effekte in Fischen seit dem Jahr 1998 konnte bisher nicht nachgewiesen werden.

Diskussion Cytopathologie, allgemeine Cyto- und Embryotoxizität, Teratogenität und Gentoxizität im Unteren Neckar ergänzen sich zu einem Syndrom, das bei der Interpretation von Artenfehlbeträgen in der Zusammensetzung der Fischfauna zu berücksichtigen ist. Im Vergleich mit Weightof-Evidence-Studien an anderen größeren süddeutschen 
Fließgewässern zeigt der Neckar ein relativ hohes embryotoxisches, aber ein nur moderates gentoxisches Schädigungspotenzial.

Schlussfolgerungen Die Sedimente am Unteren Neckar weisen ein erhebliches ökotoxikologisches Schädigungspotenzial auf, das sich im Zustand der nativen Fischpopulationen widerspiegelt. Ein Beitrag einer Belastung durch chemische Stoffe zum Phänomen „Fischrückgang“ in Fließgewässern ist nicht auszuschließen.

Empfehlungen und Perspektiven Die in den letzten Jahrzehnten erreichte Verbesserung des ökologischen Zustands von Gewässern darf nicht als Argument für ein Aussetzen regelmäßiger biologischer Untersuchungen herangezogen werden. Fortgesetzte Umweltbeobachtung und kontinuierliches Monitoring sind weiterhin unabdingbar. Für eine angemessene Bewertung subletaler und/oder spezifischer biologischer Effekte in Organismen ist deren Populationsrelevanz zu klären. Zur Identifikation der chemischen Grundlage für die beobachteten biologischen Wirkungen bieten sich integrierte Ansätze wie etwa Effekt-dirigierte Analyse an.

Schlüsselwörter Comet-Assay · Cytopathologie · Cytotoxizitätstest $\cdot$ Fischembryotest $\cdot$ Fischrückgang · Gentoxizität · Mikrokerntest · Teratogenität · Weight-of-Evidence

\section{Fish populations under stress - the example of the Lower Neckar River}

Abstract Background, aim, and scope Reports about declines or unusual structures of fish populations in native aquatic systems in Central Europe and North America are in sharp contrast to an obvious improvement of general water quality. The Neckar River may serve as an example of a formerly severely contaminated freshwater system in Southern Germany, the ecological situation of which could be substantially improved over the last three decades. Nevertheless, there are still deficits in the composition of the fish fauna, which cannot be explained by conventional chemical-analytical, hydromorphological and limnological methodologies. Therefore, in search of explanations for ecological deficits, ecotoxicological investigations with an increasing focus on sediment contamination have been performed along the Lower Neckar River over a period of 10 years. In addition to sediment tests, fish populations were screened for genotoxic and embryotoxic effects as well as alterations in the structure of central metabolic organs such as the liver.

Materials and methods Roach (Rutilus rutilus) and gudgeon (Gobio gobio) from the Lower Neckar River were studied with respect to histo- and cytological alterations of the liver as well as the induction of genotoxicity in liver, gut, gills and blood cells by means of the comet and micronucleus assays. At the same time, both native sediments and acetonic sediment extracts were tested for toxicity to zebrafish (Danio rerio) embryos and permanent fish cell cultures.

Results Massive disturbances of the liver ultrastructure indicate severe stress in the fish from the Lower Neckar River despite good supply of nutrition. Both cyto- and embryotoxicity tests document a considerable toxic potential of sediments from the Lower Neckar River, and results of both the comet assay and the micronucleus test provide evidence of the presence of genotoxic agents in the sediments and their effects in fish. There has been no decrease of genotoxicity over the last 10 years.

Discussion Cytopathology in conjunction with general cytoand embryotoxicity in fish from the Lower Neckar River contribute to a syndrome which cannot be neglected in the interpretation of abnormal compositions of fish populations. In comparison to weight-of-evidence studies at other river systems in Southern Germany, the Neckar is characterized by an elevated embryotoxic but by a relatively moderate genotoxic potential.

Conclusions The ecotoxicological burden of sediments at the Lower Neckar River is mirrored in the condition of native fish populations. A potential contribution of chemical contamination to the phenomenon of fish declines in aquatic ecosystems cannot be ignored.

Recommendations and perspectives The improvement of the ecological status of freshwater systems may not be abused as an argument to discontinue biological monitoring programs. Rather, continuous surveillance of the environment and in-depth investigations into the consequences of chemical contamination are indispensible. For an adequate appreciation of the ecological relevance of sublethal and/ or specific biological effects, their impact on population structure and function remains to be elucidated further. For the identification of the chemical basis of biological effects, methodologies such as effect-directed analysis appear to be promising approaches.

Keywords Comet-Assay · Cytopathology · Cytotoxicity · Fish decline $\cdot$ Fish embryo test $\cdot$ Genotoxicity . Micronucleus test $\cdot$ Teratogenicity $\cdot$ Weight-of-evidence

\section{Problemstellung}

Der Neckar kann in vielerlei Hinsicht als Modell für die Belastung von Fließgewässern in Mitteleuropa gelten, da er einer Vielzahl anthropogener Nutzungen unterworfen ist: Um der Hochwassergefahr zu begegnen und den Fluss trotz stark schwankender Wasserführung als Großschifffahrtsstrasse (Transportvolumen: 8-10 Mio t/a; Weiß 2007) nutzen zu können, wurde er von 1925 bis 1968 zwischen 
Plochingen und Mannheim auf einer Länge von $203 \mathrm{~km}$ mit insgesamt 27 Staustufen reguliert (Kobus und Bürkle 1996; Müller et al. 1993), so dass der Neckar heute den Charakter eines natürlichen Fließgewässers weitgehend verloren hat. Gewässermorphologisch sind insbesondere die Uferbereiche infolge der wasserbaulichen Maßnahmen entlang des gesamten schiffbaren Abschnitts als naturfern einzustufen.

Der Fluss hat ein Einzugsgebiet von $14.000 \mathrm{~km}^{2}$, in dem ca. 5 Mio. Menschen leben. Er durchfließt mit den Ballungsräumen Stuttgart, Heilbronn und Rhein-Neckar wichtige wirtschaftliche Zentren. Dem stetig steigenden Abwasseraufkommen wurde mit einem konsekutiven Ausbau von Kläranlagen begegnet, so dass die Gewässergüte des Neckars von der Gütestufe III-IV (sehr stark verschmutzt) im Jahr 1975 auf II-III (kritisch belastet) bzw. II (mäßig belastet) im Jahr 1990 gesenkt werden konnte (Schaal und Bürkle 1993). Entlang des Neckars sind 36 Kläranlagen (davon 9 Großkläranlagen) in Betrieb; hinzu kommen ca. 80 weitere Kläranlagen an den Nebenflüssen (Steidle 2007). Über weite Abschnitte im Mittellauf besteht das Wasser des Neckars bis zu 30\% aus Abwasser; in regenarmen Sommern dürfte dieser Wert deutlich überschritten werden. Unabhängig davon unterliegt der Fluss auch weiterhin einer als kritisch einzustufenden thermischen Belastung $\left(\right.$ ca. $3{ }^{\circ} \mathrm{C}$ ), die allerdings seit den 1970 er-Jahren trotz einer Steigerung der Nennleistung der Kraftwerke von 2300 MW im Jahr 1970 (Ministerium für Ernährung 1973) auf nahezu 7000 MW im Jahr 2007 aufgrund des Baus von Kühltürmen nicht mehr weiter anstieg (Steidle 2007). Neben weiteren Belastungen in Form von unkontrolliertem Oberflächenabfluss, Fischerei, Sand- und Kiesgewinnung sowie Naherholung und Tourismus kommt schließlich als „biologische Bedrohung“ die stark zunehmende, jedoch schwer einzuschätzende Einwanderung von Neozoen hinzu (Rey et al. 2005).

Für die biologische Vielfalt von besonderer Bedeutung ist schließlich der Eintrag toxischer Substanzen, der zusammen mit den anderen Belastungen zu einer deutlichen Verarmung der Besiedlung des Gewässers und einem signifikanten Rückgang der Fischpopulationen geführt hat (Steidle 2007). Nachdem der Neckar in der 1970erJahren noch als einer der am stärksten belasteten Flüsse Süddeutschlands (Förstner und Müller 1974) galt, führten Verbesserungen in der Reinigung von Abwässern zu einer deutlichen Reduktion der Verschmutzung (Hollert et al. 2000a; LfU-Baden-Württemberg 2002; Müller et al. 1993; Pinter 1986). Wie an zahlreichen anderen Flüssen in Mitteleuropa und Nordamerika (Burkhardt-Holm 2008; Burkhardt-Holm et al. 2005; Cook et al. 2003; de Lafontaine et al. 2002; Faller et al. 2003; Keiter et al. 2006) hat jedoch die Verbesserung der über klassische Parameter definierten Gewässergüte auch am Neckar nicht zu einer entsprechenden Erholung der Fischpopulationen geführt. Von den ursprünglich 44 im Neckar nachgewiesenen Fischarten (Günther 1853; Lauterborn 1938; Wnuck 2000) sind heute nur noch 34 nachzuweisen - allerdings in z.T. noch immer sehr stark dezimierten Populationen, die zudem einen sehr unnatürlichen Aufbau zeigen (Marthaler und Pawlowski 2005; vgl. auch Wurm 2001 für die Donau). Dass vor allem rheophile Fischarten im Neckar stark zurückgedrängt wurden, ist durch den Ausbau zur Schifffahrtsstraße noch relativ leicht zu erklären. Ansonsten wird zunehmend eine kontinuierliche Belastung mit einer Vielzahl persistierender organischer Schadstoffe als Erklärung für die Artendefizite herangezogen (Burkhardt-Holm et al. 2005; Burkhardt-Holm und Segner 2002; Cook et al. 2003; de Lafontaine et al. 2002; Faller et al. 2003; Hollert et al. 2000a; Keiter et al. 2008), wobei auch am Neckar in gleicher Weise wie in anderen aquatischen Systemen (Ahlf et al. 2002; Brack et al. 2005; Chen und White 2004; Power und Chapman 1992) neben dem freien Wasserkörper vor allem auch Schwebstoffe und Sedimente als Quelle für eine Kontamination von Organismen diskutiert werden (Hollert et al. 2000a, 2002a,b; Kern und Westrich 1995). Analog zu parallelen Weight-of-Evidence-Studien an der Donau (Keiter et al. 2006, 2008; Seitz et al. 2008) und am Rhein (Braunbeck et al. 2005; Kosmehl et al. 2004, 2006, 2007) wurden daher am Unteren Neckar nahe Heidelberg wiederholt Rotaugen (Rutilus rutilus) und Gründlinge (Gobio gobio) aus dem Unteren Neckar hinsichtlich histo- und cytopathologischer Veränderungen in der Leber sowie der Induktion gentoxischer Effekte in Leber-, Darm-, Kiemenund Blutzellen mit Hilfe von Comet- und Mikrokern-Assay untersucht. Parallel wurden Sedimente aus Aue-ähnlichen Randbereichen am Unteren Neckar in nativem Zustand sowie nach acetonischer Extraktion hinsichtlich teratogener Wirkungen im Fischembryotest mit dem Zebrabärbling (Danio rerio) geprüft. Als Ergänzung wurden die Sedimente schließlich hinsichtlich ihrer (cyto-)toxischen Wirkung auf Fischzellen untersucht.

\section{Material und Methoden}

Die Untersuchung der Fische aus dem Neckar bzw. die Prüfung von Wasser-, Schwebstoff- und Sedimentproben erfolgten im Rahmen einer Weight-of-Evidence-Studie (Hollert et al. 2002a,b, 2003; Brack et al. 2005; Keiter et al. 2006) zur ökotoxikologischen Belastung des Unteren Neckars (Abb. 1). Im Rahmen einer größeren Testbatterie wurden histo- und cytologische Veränderungen in der Leber von Fischen aus dem Neckar, cytotoxische Effekte in Fischzellen, akut toxische und teratogene Wirkungen in Fischembryonen sowie gentoxische und mutagene Wirkungen in Fischen und Fischzellen untersucht. 


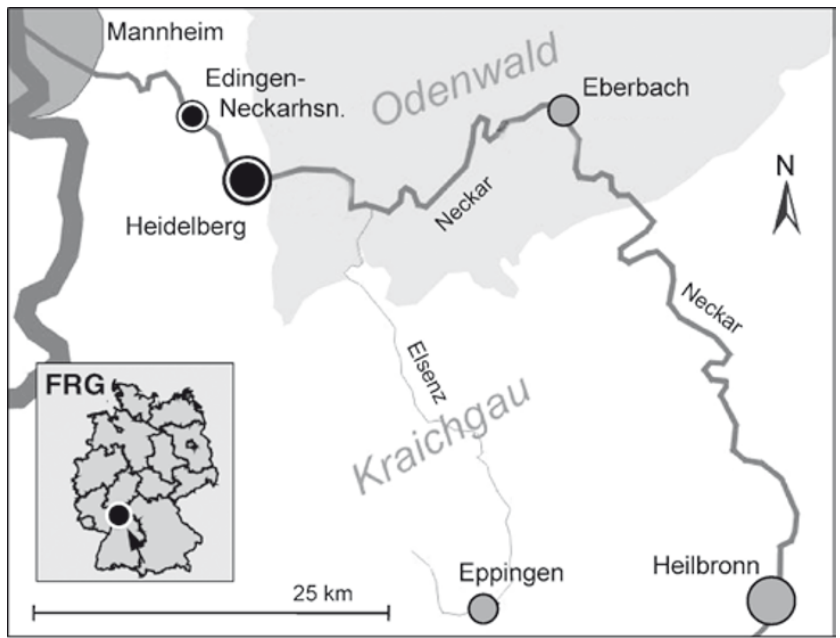

Abb. 1 Der Neckar mündet bei Mannheim in den Rhein. Die Probenahmestellen „Heidelberg“ und „Krottenneckar/Edingen-Neckarhausen“ liegen am sog. „Unteren Neckar“ kurz vor seiner Mündung. Neu gezeichnet auf der Basis von Hollert et al. (2003)

\subsection{Probenahme und -aufarbeitung}

Fische Mit Hilfe eines Senknetzes oder im Rahmen von Elektrobefischungen (November 2004) wurden in den Jahren zwischen 1998 und 2006 am Unteren Neckar (unterhalb der Schleuse Heidelberg; s. Abb. 1) bzw. im Bereich des Naturschutzgebiets „Krottenneckar“ bei Edingen-Neckarhausen; Abb. 2) wiederholt subadulte bzw. geschlechtsreife Rotaugen (Rutilus rutilus) bzw. Gründlinge (Gobio gobio) beiderlei Geschlechts mit einer Länge zwischen 15 und $20 \mathrm{~cm}$ bzw. 9 bis $13 \mathrm{~cm}$ gefangen. Die Tiere wurden unter kontinuierlicher Belüftung umgehend ins Labor transpor- tiert und dort für die jeweiligen Untersuchungen direkt aufgearbeitet. Alternativ wurden die Tiere mehrere Monate als sog. ,Laborkontrolle“ in chlorfreiem Trinkwasser $\left(24^{\circ} \mathrm{dH}\right)$ in einem Durchflusssystem bei einer jahreszeitlich angepassten Temperatur zwischen 12 und $18^{\circ} \mathrm{C}$ und einem Tag-/ Nacht-Rhythmus von 12:12 Stunden gehalten und täglich mit TetraMin Flockenfutter (max. 1\% Körpergewicht; Tetra Werke, Melle) gefüttert. Als zweite Kontrollgruppe wurden Rotaugen von einer kommerziellen Fischzucht (Riegger, Ettenheim) unter gleichen Bedingungen wie die ehemaligen Neckartiere als „Zuchtkontrolle“ mehrere Monate gehältert.

Sedimentproben Je nach Wassertiefe und Zugänglichkeit wurden die Sedimentproben mit Hilfe eines Van-Veen-Sedimentgreifers (Wildco, Wildlife Supply Company, Buffalo, USA) oder einer Edelstahlschaufel entnommen. Um kleinräumige Varianzen (Ingersoll et al. 1997) zu kompensieren, wurden von jeder Probestelle jeweils vier Einzelproben aus den oberen $10-15 \mathrm{~cm}$ des Sediments auf einer Fläche von etwa $4 \mathrm{~m}^{2}$ homogenisiert, im Labor bei $-30^{\circ} \mathrm{C}$ tiefgefroren und bei 2,6 mbar gefriergetrocknet (Alpha 1-4, Christ, Osterode). Nach Sieben über ein $2 \mathrm{~mm}$-Edelstahlgitter wurden $20 \mathrm{~g}$ trockenes Sediment in $350 \mathrm{ml}$ Aceton p. a. mit 10 Zyklen in $14 \mathrm{~h}$ extrahiert (Hollert und Braunbeck 1997). Nach Einengen bei $39^{\circ} \mathrm{C}$ und $400 \mathrm{mbar}$ (Rotationsverdampfer Heidolph, Kehlheim) und Evaporation mit $\mathrm{N}_{2}$ fast bis zur Trockene wurden die Extrakte in $1 \mathrm{ml}$ Dimethylsulfoxid (DMSO; Sigma, Deisenhofen) aufgenommen (Hollert et al. 2000a).

\subsection{Elektronenmikroskopie}

Die Leber als zentrales Stoffwechselorgan wurde als „Spiegel der Umwelt" (Storch 1985) untersucht, um sowohl chemikalieninduzierte Veränderungen in Fischen in der aqua-

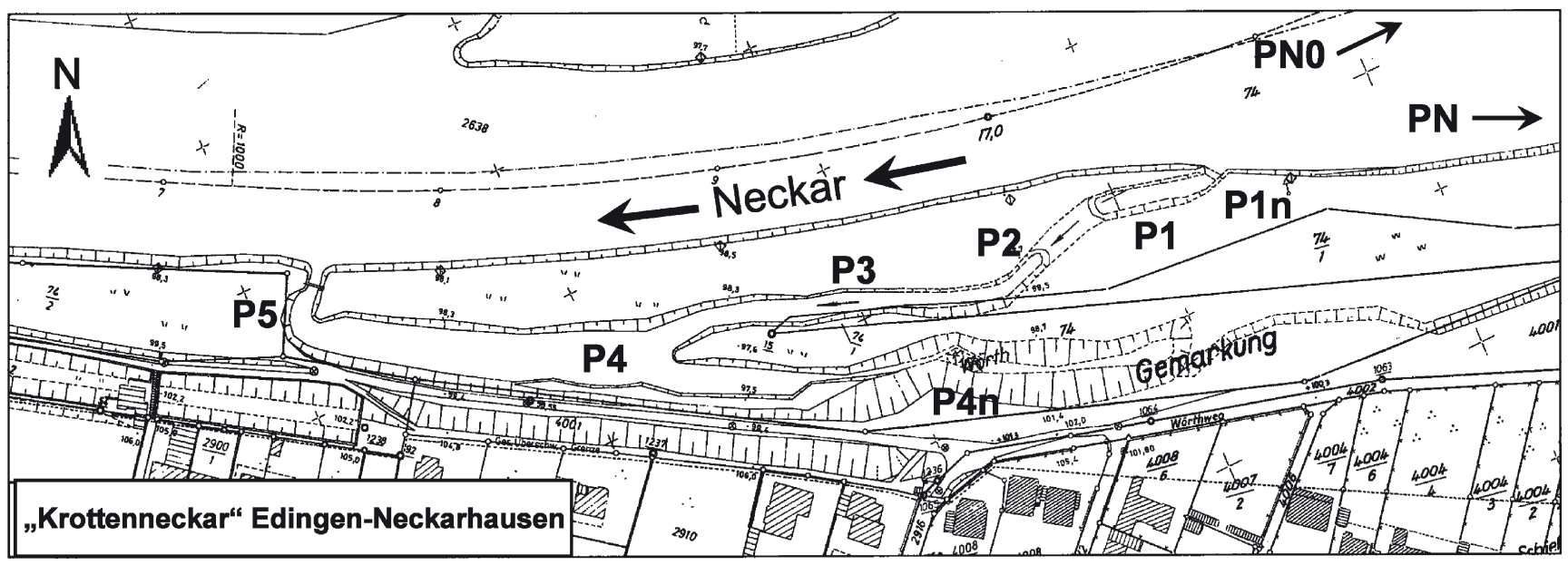

Abb. 2 Das Untersuchungsgebiet „Krottenneckar“ bei Edingen-Neckarhausen am Unteren Neckar umfasst einen schmalen Wasserstreifen, der sich zwischen den Flusskilometern 17,08 und 16,75 parallel zum Neckar erstreckt und entlang der Probenahmestellen P1 bis P5 beprobt wurde. Zwischen P1 und P2 fällt das Gerinne des „Krottenneckars“ bei Niedrigwasser trocken. Die Sedimente an den Probenahmestellen P1n und P4n wurden nur im Jahr 2008 untersucht. Als interne Referenzstellen dienten zwei Stellen am Ufer des Neckars (2004: PN; 2008: PN0) 
tischen Umwelt (Braunbeck 1998; Braunbeck und Völk1 1993) als auch allgemein mit einer Beeinträchtigung der Gesundheit der Fische einhergehende Symptome aufzuzeigen (Konradt und Braunbeck 2001; Strmac und Braunbeck 2001; Strmac et al. 2002; Triebskorn et al. 2001). Die Probenahme, Fixierung und elektronenmikroskopische Untersuchung erfolgte wie bei Braunbeck et al. (1987), Hofer et al. (1997) bzw. Oulmi et al. (1995) beschrieben.

\subsection{Gentoxizitätstests}

Comet-Assay Der Comet-Assay nach Belpaeme et al. (1998) bzw. Singh et al. (1991) wurde in der Modifikation von Schnurstein und Braunbeck (2001) bzw. Kosmehl et al. (2004, 2008) auf die intakten Fische bzw. Fischzellkulturen (RTL-W1; Lee et al. 1993; Nehls und Segner 2001) angewandt. Die Auswertung erfolgte über ein automatisches Bildanalysesystem (Optilas, München) und die Auswertungssoftware Comet 3.0 $0^{\mathrm{TM}}$ (Kinetic Imaging, Liverpool, UK); die Ergebnisse wurden als Tail-Moment (Schnurstein und Braunbeck 2001, Seitz et al. 2008) angegeben.

Mikrokerntest Der Mikrokerntest (Schmid 1975) wurde analog zu Al-Sabti und Harding (1990), Ayllon und GarciaVazquez (2000), Reifferscheid et al. (2008) bzw. Russo et al. (2004) in den Erythrocyten aus Rotaugen aus dem Unteren Neckar durchgeführt, wobei parallel auch Kerndeformationen erfasst wurden. Die Angabe der Ergebnisse erfolgte als Mikrokernrate, d.h. dem Anteil der Zellen mit Mikrokernen bzw. Deformationen an der Gesamtzahl von 1000 bzw. 2000 untersuchten Zellen (Kosmehl et al. 2008).

\subsection{Fischembryotoxizitätstests}

Der Fischembryotoxizitätstest (Nagel 2002) wurde in Abhängigkeit vom Jahr der Probenahme in den jeweils neuesten Aktualisierungen nach Braunbeck et al. (2005) bzw. Lammer et al. (2009) durchgeführt. Als Besonderheit schreibt die letzte Aktualisierung eine Absättigung der 6-Well-Platten vor Beginn der Exposition über mindestens $24 \mathrm{~h}$ vor und erstreckt sich über eine Expositionsperiode von bis zu 108 h, dem Zeitpunkt der ersten Nahrungsaufnahme bei Embryonen des Zebrabärblings (Lammer et al. 2009). Die Belastung der Embryonen mit nativen Sedimenten bzw. acetonischen Sedimentextrakten erfolgte nach der Beschreibung von Hollert et al. (2003) bzw. Kosmehl et al. (2006, 2008).

\subsection{Cytotoxizitätstests}

Cytotoxizitätstests wurden nach Segner und Lenz (1993) mit den permanenten Fischzelllinien RTG-2 (Braunbeck 1995, Castaño und Gómez-Lechón 2005, Kosmehl et al. 2004) bzw. RTL-W1 (Keiter et al. 2008; Kosmehl et al. 2004; Lee et al. 1993) nach einer Expositionsdauer von 48 bis $72 \mathrm{~h}$ mit der lysosomalen Retention von Neutralrot (2-Methyl3-amino-7-dimethylaminophenazin) als Endpunkt (Borenfreund und Puerner 1985) bestimmt.

\section{Ergebnisse}

3.1 Elektronenmikroskopische Veränderungen in der Leber von Rotaugen aus dem Unteren Neckar

Nach einer zweimonatigen Hälterung unter Laborbedingungen in Heidelberger Trinkwasser entsprach die Ultrastruktur der Leber der Rotaugen aus dem Unteren Neckar (Abb. 3) jener von Cypriniden, wie sie in der Literatur nach Perfusionsfixierung beschrieben wurde (Braunbeck und Appelbaum 1999; Braunbeck et al. 1987, 1989; Segner und Braunbeck 1988, 1990): Um einen zentralen Kern mit relativ wenig Heterochromatin lagern sich mehrere konzentrische Stapel von rauem endoplasmatischem Retikulum (RER), in das einige Mitochondrien und ein Golgi-Apparat eingestreut sind, der bei weiblichen Tieren ebenso wie das RER sehr viel stärker entwickelt ist als bei männlichen Fischen. Dieser zentrale organellenhaltige Teil des Cytoplasmas ist streng von den peripheren Zellarealen getrennt (,,intrazelluläre Kompartimentierung“; Braunbeck et al. 1990), in denen neben umfangreichen Glykogenreserven auch Lipidtropfen zu finden sind. Unmittelbar unter dem Plasmalemma finden sich einige wenige isolierte RER-Zisternen. Mit Einschränkungen gilt diese Beschreibung auch für die Rotaugen

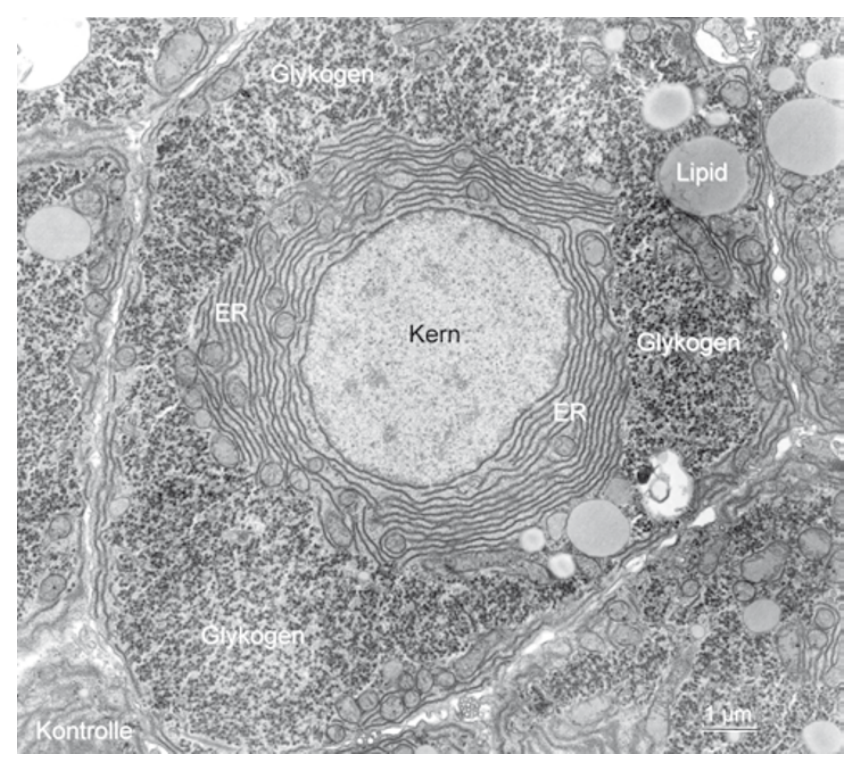

Abb. 3 Das ultrastrukturelle Erscheinungsbild der Leber von Rotaugen, die über einen längeren Zeitraum als unbelastete Kontrollen im Labor gehalten wurden, ist durch eine klare Trennung in einen zentralen organellenhaltigen Cytoplasmaabschnitt, der vom rauen endoplasmatischem Retikulum (ER) dominiert wird, und periphere Glykogenareale gekennzeichnet 


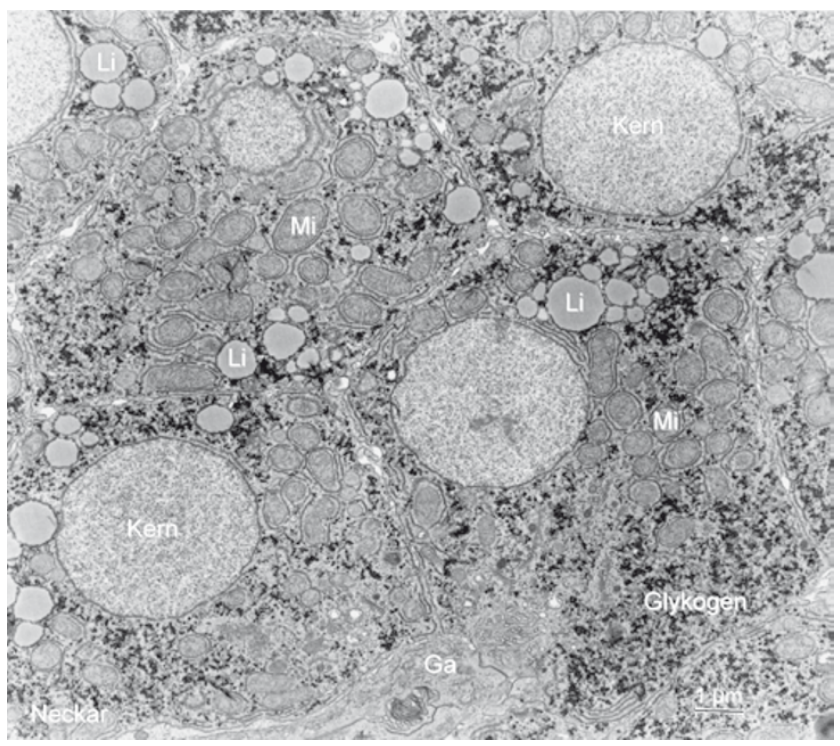

Abb. 4 Die insgesamt deutlich kleineren Hepatocyten von Rotaugen aus dem Unteren Neckar, die unmittelbar nach dem Fang fixiert wurden, sind vor allem durch eine starke Reduktion von endoplasmatischem Retikulum und Glykogen charakterisiert. $G a$ galleausleitendes System, Li Lipid, Mi Mitochondrien

aus der Zucht. Im Gegensatz dazu erscheinen die Hepatocyten von Rotaugen, die direkt nach Entnahme aus dem Unteren Neckar fixiert wurden, ungeordnet. Reservestoffe wie Glykogen und Lipid sind deutlich vermindert, vor allem aber sind die umfangreichen Stapel des RER signifikant reduziert (Abb. 4).

\subsection{Gentoxische Effekte in Rotaugen}

und Gründlingen aus dem Unteren Neckar

nach Befunden im Comet- und Mikrokern-Assay

Seit 1998 wurden adulte Fische aus dem Unteren Neckar in unregelmäßiger Folge wiederholt hinsichtlich gentoxischer

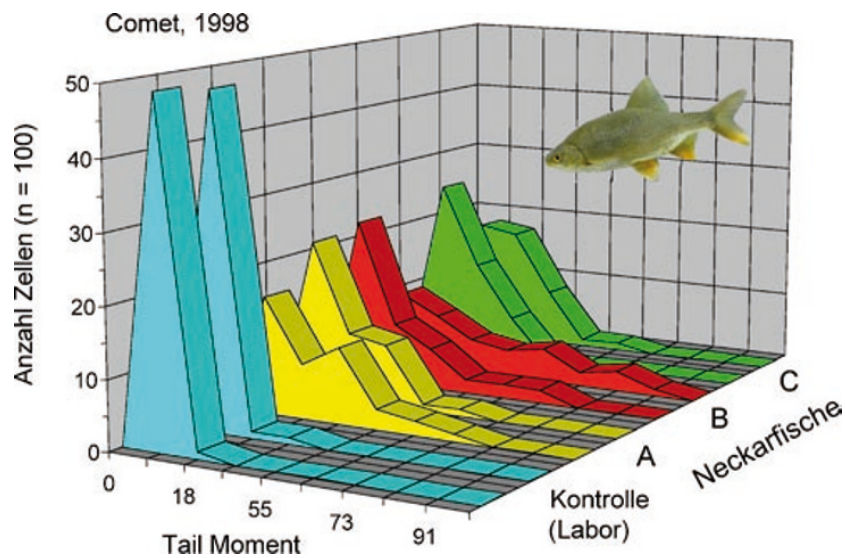

Abb. 5 Gentoxische Effekte in adulten Rotaugen (Rutilus rutilus) aus dem Unteren Neckar im Comet-Assay: Drei von zehn Individuen zeigten eine starke Zunahme des Tail-Moments (relative Intensität der DNA im Kometen im Vergleich zur Kontrolle mal Kometenlänge) gegenüber den über drei Monate im Labor gehaltenen Kontrollen. Daten aus zwei Replikaten, wobei jeweils 100 Zellen pro Individuum ausgewertet wurden

Effekte untersucht, wobei sich bei jeder Probenahme zwischen 20 und $30 \%$ der untersuchten Rotaugen als stark positiv im Comet-Assay erwiesen; Abb. 5 zeigt drei Beispiele im Vergleich zu Fischen, die über drei Monate als Kontrolle im Labor gehalten worden waren.

Die Befunde an Rotaugen konnten durch Untersuchungen an Gründlingen (Gobio gobio) bestätigt werden, die ebenfalls im Jahr 1998 im Neckar gefangen worden waren (Tabelle 1): Vor allem in den Kiemenzellen, aber auch in Darm- und Leberzellen der Neckar-Gründlinge konnten signifikante Zunahmen der Kometenbildung nachgewiesen werden.

Da der Comet-Assay eher den Charakter eines Indikatortests besitzt, wurden bei einigen Probenahmen parallel Untersuchungen zur Bildung von Mikrokernen bei Rotau-

Tabelle 1 Gentoxizität in Gründlingen (Gobio gobio) direkt aus dem Neckar bei Heidelberg bzw. aus dem Neckar nach einer dreimonatigen Hälterung unter Laborbedingungen im Trinkwasser („Kontrolle“) nach Befunden im Comet-Assay im Jahr 1998

\begin{tabular}{lllll}
\hline Datum & & Hepatocyten & Kiemenzellen & Darmzellen \\
\hline 14.7.1998 & Kontrolle & $0,707 \pm 0,054$ & $0,505 \pm 0,023$ & $0234 \pm 0,034$ \\
& Neckar & $0,746 \pm 0,077$ & $2,072 \pm 0,086 * * *$ & $5,056 \pm 0,069 * * *$ \\
23.7 .1998 & Kontrolle & $0,398 \pm 0,040$ & $0,367 \pm 0,051$ & $0,418 \pm 0,069$ \\
& Neckar & $1,414 \pm 0,101 *$ & $1,967 \pm 0,143 * *$ & $3,049 \pm 0,201 * * *$ \\
4.8 .1998 & Kontrolle & $0,282 \pm 0,042$ & $0,411 \pm 0,063$ & $0,315 \pm 0,025$ \\
& Neckar & $1,062 \pm 0,088 * * *$ & $9,636 \pm 1,103 * * *$ & $7,014 \pm 0,887 * * *$ \\
18.8 .1998 & Kontrolle & $0,960 \pm 0,099$ & $0,769 \pm 0,077$ & $1,106 \pm 0,134$ \\
8.10 .1998 & Neckar & $1,310 \pm 0,112$ & $1,427 \pm 0,088 * * *$ & $1,624 \pm 0,089 * *$ \\
& Kontrolle & $0,326 \pm 0,045$ & $0,407 \pm 0,065$ & $1,025 \pm 0,117$ \\
& Neckar & $0,777 \pm 0,037 * *$ & $8,290 \pm 1,456 * * *$ & $2,894 \pm 0,176 * * *$ \\
\hline
\end{tabular}

Daten als Tail-Moment \pm Standardabweichung; Signifikanz der Abweichungen der Neckarfische von den jeweiligen Laborkontrollen nach OneWay ANOVA-on-Ranks in Kombination mit Dunnett's Test $(* \mathrm{p}<0,05 ; * * \mathrm{p}<0,01 ; \mathrm{p}<0,001$; SigmaStat 3.01; $\mathrm{n}=6-8$ Fische) 
gen und Gründlingen durchgeführt, die die Ergebnisse der Comet-Assays allerdings eindeutig bestätigten; die Mikrokernrate bei Rotaugen erwies sich dabei als grundsätzlich höher als beim Gründling (Abb. 6). Eine Wiederholung der Untersuchungen an adulten Rotaugen vom Unteren Neckar im Bereich des Naturschutzgebiets „Krottenneckar“ auf der Gemarkung der Gemeinde Edingen-Neckarhausen im Jahr 2004 (Abb. 7) ergab sogar deutlich höhere Mikrokernraten als im Jahr 1998.

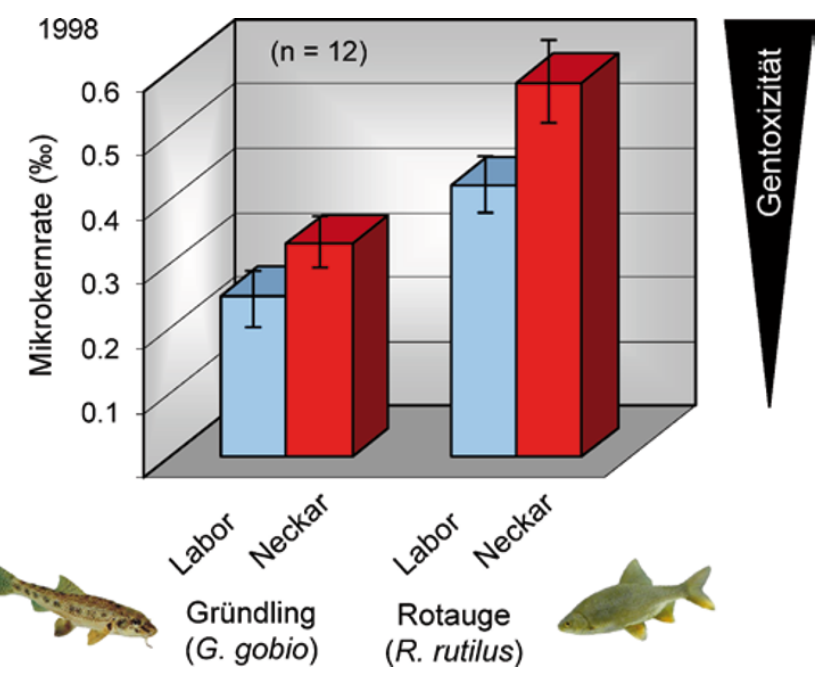

Abb. 6 Mikrokernrate in Erythrocyten aus Gründlingen (Gobio gobio) und Rotaugen (Rutilus rutilus) aus dem Unteren Neckar bei Heidelberg bzw. in Kontrollen aus dem Neckar nach dreimonatiger Hälterung im Labor (Trinkwasser) im Jahr 1998. Daten als Mittelwerte aus $n=12$ Fischen (jeweils 2000 Zellen)



Abb. 7 Mikrokernrate in Erythrocyten aus Rotaugen (Rutilus rutilus) direkt aus dem Unteren Neckar bzw. in Kontrollen aus dem Neckar nach dreimonatiger Hälterung im Labor (Trinkwasser) sowie Kontrollen aus einer Fischzucht im Jahr 2004. Die Zahlen neben den Fehlerbalken geben den Bereich der Werte an; Daten als Mittelwert aus $\mathrm{n}=10$ Fischen (jeweils 1000 Zellen)
Auch Zellen der permanenten Fischzelllinie RTL-W1 zeigten nach Belastung mit acetonischen Extrakten von Sedimentproben, die dem Naturschutzgebiet „Krottenneckar“ am Unteren Neckar auf der Gemarkung der Gemeinde Edingen-Nackarhausen entnommen worden waren, eine eindeutige Induktion der Schweife im Comet-Assay (Abb. 8: Jahr 2004), wobei die gentoxischen Effekte durch jene Proben am stärksten waren, die an Stellen mit sehr geringer Wasserbewegung und daher starker Sedimentation gezogen worden waren und folglich vor allem durch sehr feine Partikel charakterisiert waren (P3 bis P5).

\subsection{Toxizität nativer Sedimentproben}

und acetonischer Sedimentextrakte im Fischembryotest mit dem Zebrabärbling (Danio rerio)

In der Regel korrespondierte die Stärke der gentoxischen Effekte in RTL-W1-Zellen sehr gut mit der akuten Toxizität der nativen gefriergetrockneten Sedimente gegenüber befruchteten Eiern und Embryonen des Zebrabärblings (Danio rerio), d.h. die feinkörnigen Sedimente von Probenahmestellen mit relativ schwacher Durchströmung übten auch eine starke embryotoxische Wirkung aus (Abb. 9: Jahr 2004). Ein direkter Effekt einer Sauerstoffzehrung konnte weitgehend ausgeschlossen werden, da der Sauerstoffgehalt in der Wasserphase praktisch stets über $3 \mathrm{mg} / \mathrm{L}$ lag. Die embryonale Mortalität ging einher mit einer signifikanten Reduktion der Schlüpfrate nach einer Belastungsdauer von 72 und 96 h (Abb. 10, 11).

Nach Durchführung einer Sanierungsmaßnahme im Jahr 2007 war die Tendenz, dass vor allem feinkörnige Sedimen-

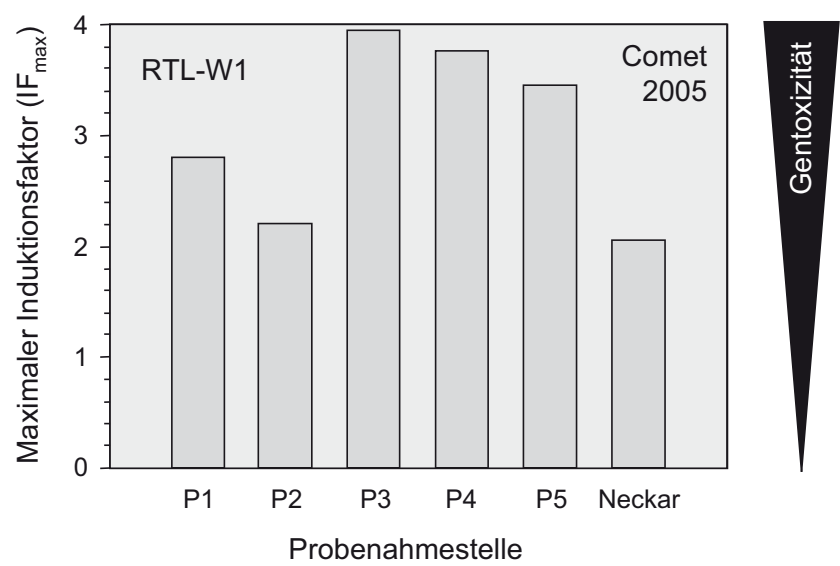

Abb. 8 Gentoxische Effekte in der permanenten Zelllinie RTL-W1 aus der Regenbogenforelle (Oncorhynchus mykiss), die im Jahr 2004 Sedimenten an verschiedenen Standorten ( $P 1$ bis $P 5)$ aus dem Naturschutzgebiet „Krottenneckar“ am Unteren Neckar bzw. Sedimentproben direkt aus dem Neckar bei Edingen-Neckarhausen exponiert worden waren, im Comet-Assay. Daten als Mittelwerte der maximalen Induktionsfaktoren für das Tail-Moment aus $\mathrm{n}=2$ unabhängigen Testansätzen (jeweils 100 Zellen) 


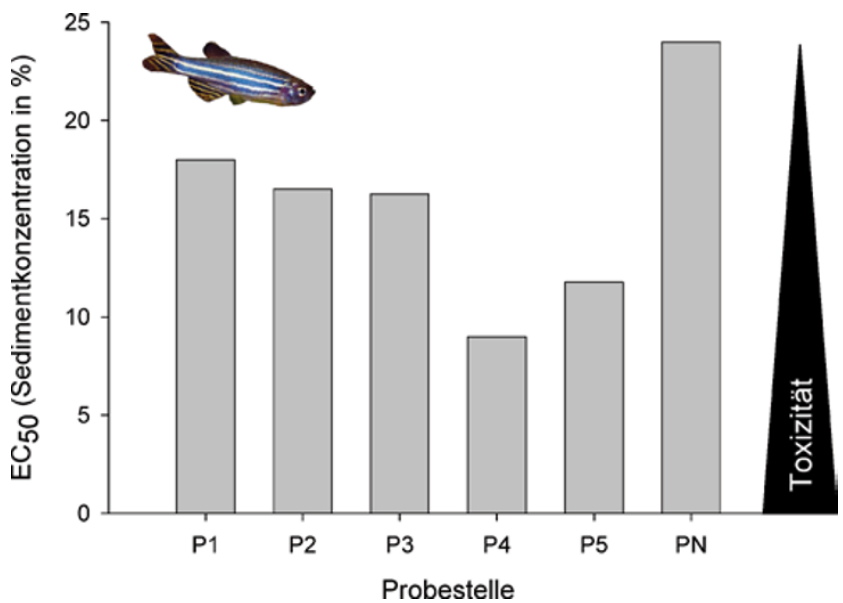

Abb. 9 Toxizität von nativen Sedimenten aus dem Naturschutzgebiet „Krottenneckar“ am Unteren Neckar im Fischembryotest mit dem Zebrabärbling (Danio rerio) nach einer Belastung über 48 Stunden. Daten als Mittelwerte aus 2 unabhängigen Experimenten im Jahr 2004 mit jeweils 20 Embryonen



Abb. 10 Schlupfrate im Fischembryotest mit dem Zebrabärbling (Danio rerio) nach Exposition gegenüber nativen Sedimenten vom Unteren Neckar (Jahr 2004, Naturschutzgebiet „Krottenneckar“) nach $96 \mathrm{~h}$ Belastung in Abhängigkeit von der Sedimentkonzentration in der Sediment-Quarzmehlmischung (\%). Daten als Mittelwerte der maximalen Induktionsfaktoren für das Tail-Moment aus $\mathrm{n}=2$ unabhängigen Testansätzen (jeweils 100 Zellen)

te ein hohes Belastungspotential aufwiesen, nicht mehr so deutlich ausgeprägt, d.h., die acetonischen Extrakte von Sedimenten, die unmittelbar am Eingang zu dem Naturschutzgebiet genommen worden waren, erwiesen sich als toxischer als die Sedimentextrakte von tiefer in dem Auebereich liegenden Probenahmestellen (Abb. 12). Insgesamt waren die Sedimentproben aus dem wenig durchflossenen Naturschutzgebiet jedoch stets deutlich toxischer als die Sedimentproben direkt aus dem Unteren Neckar, die ständig umgelagert werden. Die Sedimentprobe aus dem Neckar selbst war im Vergleich zur Prozesskontrolle mindestens doppelt so toxisch.

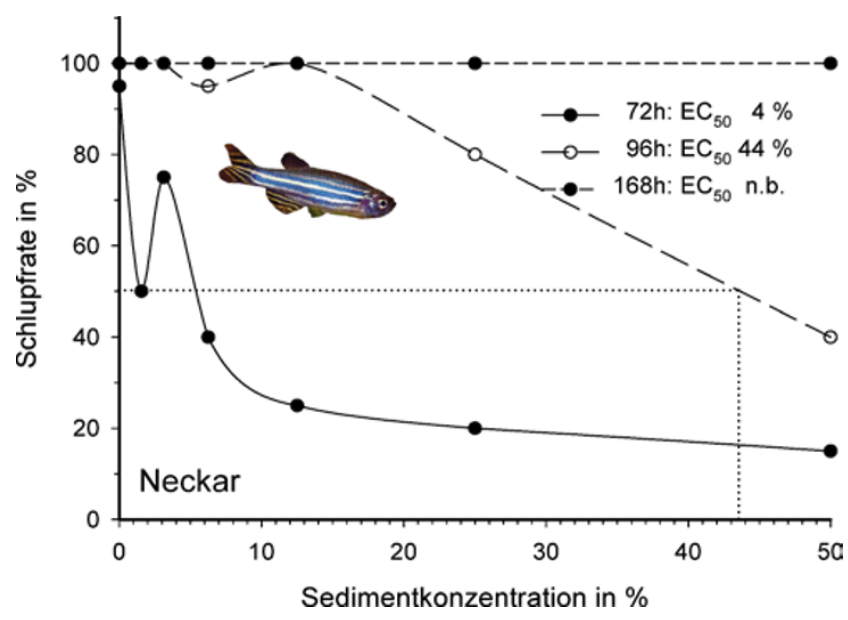

Abb. 11 Schlupfrate im Fischeitest mit dem Zebrabärbling (Danio rerio) nach Exposition gegenüber nativen Sedimenten vom Unteren Neckar (nahe Naturschutzgebiet „Krottenneckar“; Jahr 2004) nach 72, 96 und $168 \mathrm{~h}$ Belastung in Abhängigkeit von der Sedimentkonzentration in der Sediment-Quarzmehlmischung

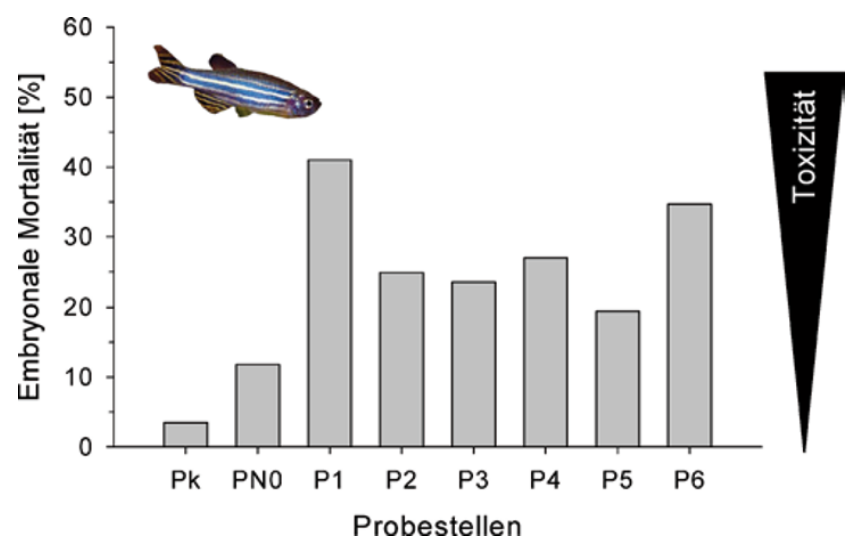

Abb. 12 Toxizität acetonischer Extrakte von Sedimenten aus dem Naturschutzgebiet „Krottenneckar“ am Unteren Neckar im Fischembryotest mit dem Zebrabärbling (Danio rerio) nach einer Belastung über 48 Stunden im Jahr 2008. Daten als Mittelwerte aus 2 unabhängigen Experimenten im Jahr 2008 mit jeweils 20 Embryonen. Äquivalent-Konzentration der Sedimentprobenextrakte: $40 \mathrm{mg}$ / $\mathrm{ml}$ SEQ in Kunstwasser. $P k$ Prozesskontrolle (Extrakt aus leerer Extraktionshülse); PNO Probenahmestelle Unterer Neckar; Pl bis P5 Probenahmestellen im Naturschutzgebiet „Krottenneckar“

\subsection{Cytotoxizität acetonischer Sedimentextrakte vom Unteren Neckar}

Im Vergleich zum Fischembryotoxizitätstest stellt der Cytotoxizitätstest mit permanenten Fischzelllinien einen echten In-vitro-Test dar; im Zusammenhang mit der vorliegenden Studie wurde er jedoch vor allem zum Ausschluss einer Interferenz zwischen Cytotoxizität und Gentoxizität durchgeführt. Die Gentoxizitätstests erfolgten stets nur bis zu Sedimentkonzentrationen, die sich im entsprechenden $\mathrm{Cy}$ - 


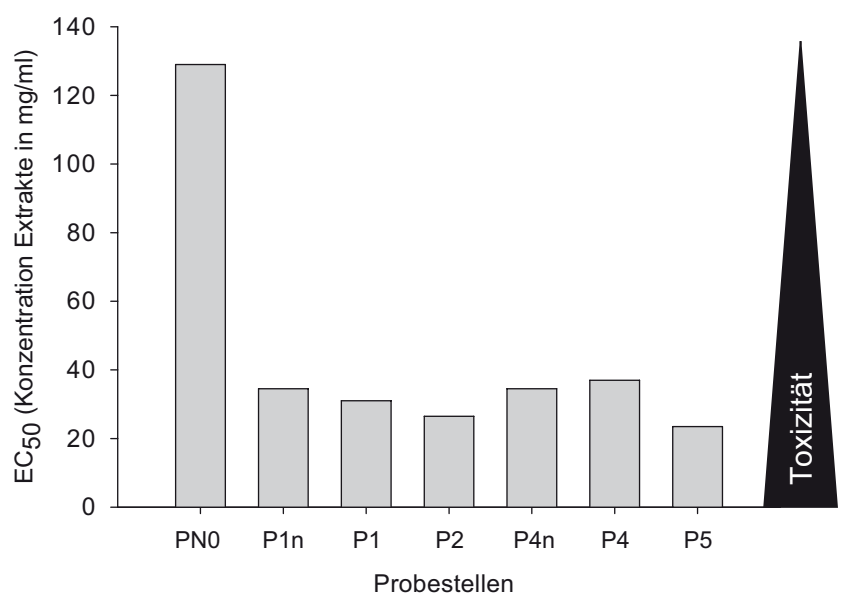

Abb. 13 Cytotoxizität acetonischer Extrakte von Sedimenten aus dem Naturschutzgebiet „Krottenneckar“ am Unteren Neckar im Cytotoxizitätstest mit der permanenten Zelllinie RTL-W1 nach einer Belastung über 48 Stunden (Jahr 2008): Das toxische Potenzial der in den Krottenneckar eingeschwemmten Sedimente ist deutlich höher als das der Sedimente im Neckar selbst. PNO Probenahmestelle Unterer Neckar; P1n bis P5 Probenahmestellen im Naturschutzgebiet „Krottenneckar"

totoxizitätstest als untoxisch erwiesen hatten. Im Jahr 2008 war die Sedimentprobe, die direkt am Neckar in der Nähe des Naturschutzgebiets „Krottenneckar“ gezogen worden war, relativ wenig toxisch, während die Sedimentproben innerhalb des Naturschutzgebiets „Krottenneckar“ selbst ein relativ hohes toxisches Potenzial aufwiesen (Brauns 2008; Abb. 13).

\section{Diskussion}

Die vorliegenden Daten belegen, dass in Fischen und Sedimenten aus dem Neckar trotz einer deutlichen Verbesserung der allgemeinen Gewässergüte (LfU-Baden-Württemberg 2002; Steidle 2007) weiterhin eine ökotoxikologische Belastung nachgewiesen werden kann. Es kam zwar durchaus zu einer partiellen Erholung der Fischbestände im Neckar (Steidle 2007), und es werden keine akuten Fischsterben mehr beobachtet. Vor allem die teratogenen und gentoxischen Effekte geben jedoch nach wie vor Anlass zur Besorgnis, da beide Endpunkte eine erhöhte Relevanz für die Entwicklung von Fischpopulationen haben können (White et al. 1998, 1999).

Methodisch gesehen ergab sich parallel zur Verbesserung der Wasserqualität auch die Notwendigkeit zu einem Wandel in der Methodik der Umweltüberwachung: (1) Die routinemäßige Überwachung der Gewässerbelastung durch ein rein chemisch-analytisches Monitoring auf prioritäre Stoffe ist grundsätzlich zu überdenken, da sich das Spektrum der relevanten Stoffe nicht nur verändert, sondern auch be- trächtlich erweitert haben dürfte. (2) Der Übergang von einer offensichtlichen Belastung durch eine limitierte Anzahl prioritärer Stoffe in relativ hohen Konzentrationen hin zu einer Belastung mit einer Vielzahl von sehr diversen Stoffen mit z. T. sehr spezifischer biologischer Wirkung in sehr niedrigen Konzentrationen bedingt eine Abkehr von klassischen ökotoxikologischen Verfahren, die sich im wesentlichen auf die Bestimmung akuter Toxizität beschränkten und eine $\mathrm{Zu}$ wendung zu weit subtileren Methoden, die nicht nur akute Mortalität, sondern eine ganze Palette von spezifischen Wirkungen anzeigen (Segner und Braunbeck 1998). Eine Kombination verschiedener Testverfahren mit unterschiedlichen Endpunkten auf verschiedenen Ebenen biologischer Organisation wird dadurch unabdingbar (Braunbeck 1996; Castaño et al. 2003; Escher et al. 2005; Hinton et al. 2001; Keiter et al. 2006, 2008; Navas et al. 2006; Scheil et al. 2008; Segner und Braunbeck 1998; Zahn et al. 1996) - eine „Testbatterie“ also, die nicht verschiedene Organismen (vgl. z. B. Davoren et al. 2005), sondern verschiedene funktionelle und strukturelle Endpunkte vereint.

In der vorliegenden Studie wurde eine Auswahl von Parametern untersucht, die für Fische als Zielorganismen von Bedeutung sein können: (1) cytopathologische Veränderungen in der Leber als genereller Indikator für den Gesundheitszustand der Fische im Unteren Neckar; (2) akute Cyto- und Embryotoxizität als Spiegel allgemeiner akuter Toxizität; (3) Embryotoxizität zusätzlich als Ausdruck teratogener Wirkungen; (4) Gentoxizität als potenzieller Anzeiger einer generationenübergreifenden Schädigung. Eine vollständige Weight-of-Evidence-Studie sollte natürlich deutlich mehr Verfahren vereinigen (Keiter et al. 2006); weitere ökotoxikologische Untersuchungen wurden von Duerr et al. (1996) sowie Hollert et al. (1996; 2000a,b; 2002a,b) publiziert.

Das elektronenmikroskopische Erscheinungsbild der Leber der Rotaugen aus dem Unteren Neckar belegt eindeutig eine erhebliche Stresssituation der Fische (Braunbeck 1989, 1994, 1998; Hinton et al. 2001; Segner und Braunbeck 1998). Insbesondere die schwache Entwicklung des Proteinsyntheseapparates (endoplasmatisches Retikulum, GolgiApparat) deutet auf eine Störung von Protein-, Lipid- und Lipoproteinsynthese hin (Segner und Braunbeck 1998); das fast vollständige Fehlen zellulärer Reservestoffe ist in Anbetracht des generell guten Nahrungsangebots im Unteren Neckar (gute Entwicklung des Makrozoobenthos) ebenfalls sicher nicht als Normalzustand zu interpretieren (Braunbeck 1992).

Die Mortalität im Fischembryotest infolge einer Belastung mit nativen Sedimenten vom Unteren Neckar ist im Vergleich mit analogen, z.T. früheren Untersuchungen am Neckar (Hollert et al. 2000a), im Neckar-Einzugsgebiet (Hollert et al. 2003), an der Donau (Seitz 2005) und am Oberrhein (König 2002) als relativ hoch einzustufen (Abb. 14). Während in den genannten Vergleichsstudien 
meist eine breite Streuung der $\mathrm{EC}_{50}$-Werte und nur für einzelne Probenahmestellen Werte herunter bis unter 10\% der nativen Sedimentkonzentration gemessen wurden, ergaben die Untersuchungen im Naturschutzgebiet „Krottenneckar“ im Jahr 2004 durchgehend EC $_{50}$-Werte zwischen 10 und $20 \%$. Diese nicht unerhebliche Toxizität der Sedimente gerade gegenüber frühen Entwicklungsstadien von Fischen kann durchaus als einer der Gründe für die Beobachtung herangezogen werden, dass vor allem über das Winterhalbjahr auch am Unteren Neckar beträchtliche Anteile der Jährlinge verschwinden.

Die Befunde zur Embryotoxizität decken sich hierbei weitgehend mit den Erkenntnissen zur Cytotoxizität, d.h., die Schadstoffe, die offensichtlich an die Sedimentpartikel adsorbiert sind, üben keine toxische Wirkungen auf spezielle Mechanismen in intakten Organismen aus, sondern wirken generell zelltoxisch. Von Bedeutung ist in diesem Zusammenhang, dass die Untersuchungen zumeist mit nativen Sedimenten durchgeführt wurden, also durchaus ein ökologisch sehr relevantes Expositionsszenario gewählt wurde (Hollert et al. 2003). Die Tatsache, dass die relativ feinen Sedimente, die sich im Bereich des Naturschutzgebiets „Krottenneckar“ ablagern, deutlich toxischer wirken als Sedimente direkt aus dem Neckar, die vor allem durch die Schifffahrt kontinuierlich relativ starker Wasserbewegung und daher Umlagerung ausgesetzt sind, spricht dafür, dass die Schadstoffe vor allem über sehr feine Schwebstoffpartikel mit hohem Gehalt an organischen Komponenten verfrachtet werden.

Im Gegensatz dazu ist das Ausmaß der Induktion von Kometen durch Sedimente vom Unteren Neckar im CometAssay mit permanenten Fischzelllinien im Vergleich zu Se-

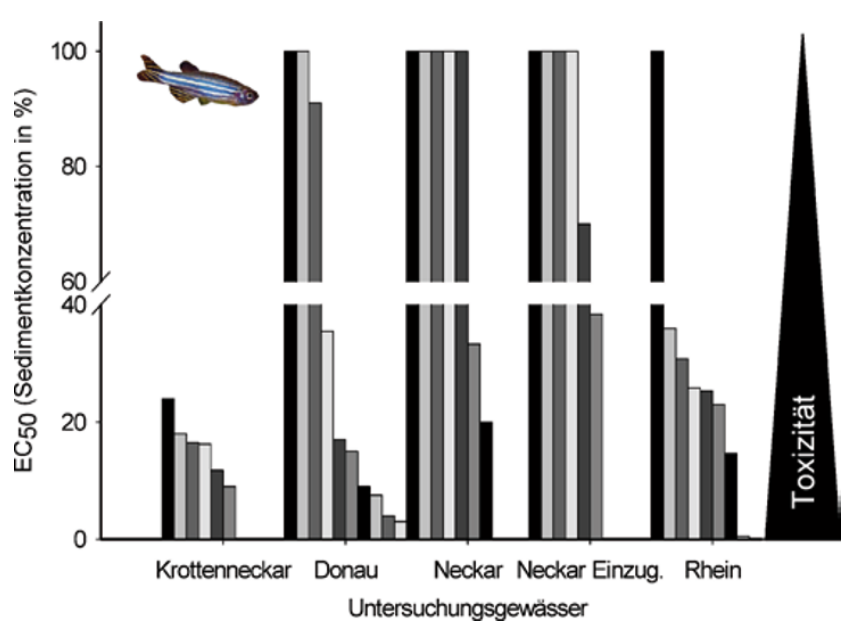

Abb. 14 Vergleich der Mortalität (48 h) im Fischembryotest mit dem Zebrabärbling (Danio rerio) mit nativen Sedimenten von „Krottenneckar", Donau (Seitz 2005), Neckar (Hollert et al. 2000b), Neckar-Einzugsgebiet (Hollert et al. 2003) und Oberrhein (König et al. 2002); jeweils mehrere Probestellen

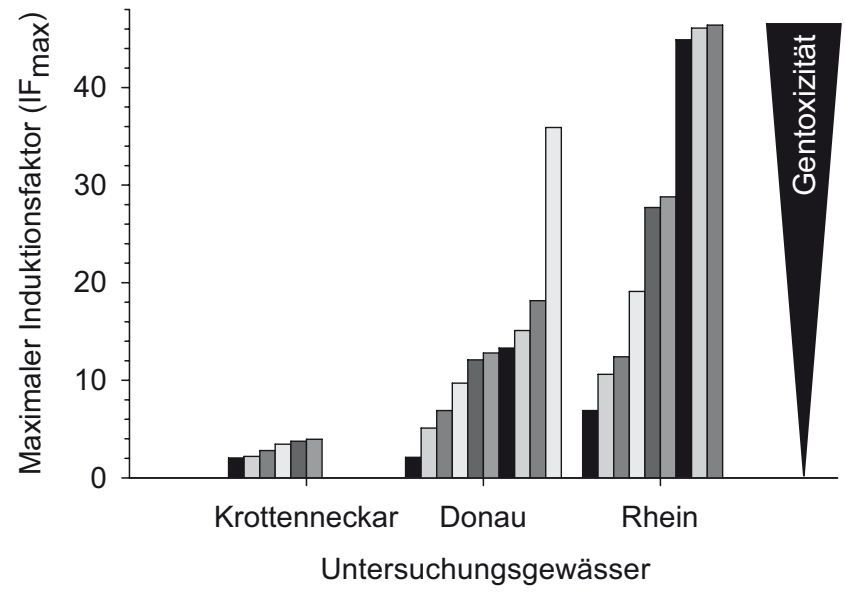

Abb. 15 Vergleich der maximalen Induktionsfaktoren $\left(I F_{\max }\right)$ im Comet-Assay mit acetonischen Sedimentextrakten und RTL-W1Zellen vom „Krottenneckar“ sowie von Donau (Böttcher 2005) und Rhein (Kosmehl et al. 2004); jeweils mehrere Probestellen

dimentproben von Rhein und Donau (Böttcher 2005; Seitz et al. 2008) als eher gering einzustufen (Abb. 15). Gemäß einer Einschätzung von Schnurstein (2000) sind Tail-Moments über 5, die sowohl von Rotaugen als auch Gründlingen aus dem Unteren Neckar sehr wohl erreicht werden, jedoch ebenfalls als Indikatoren für eine deutliche Schädigung der DNA zu interpretieren (Tabelle 2). Obwohl der Comet-Assay inzwischen in zahlreichen Studien erfolgreich eingesetzt wurde (Cotelle und Ferard 1999; Fairbairn et al. 1995; Kosmehl et al. 2004; McKelvey-Martin et al. 1993; Mitchelmore und Chipman 1998), ist doch zu bedenken, dass er nur eine Indikatorfunktion für eine Schädigung besitzt, jedoch nicht notwendigerweise mit einer permanenten Schädigung der DNA einhergehen muss (Braunbeck et al. 2003).

Im Gegensatz zu dem „Durchgangsphänomen“ DNAStrangbruch als Endpunkt im Comet-Assay stellt der Verlust von Chromosomenbruchstücken oder ganzen Chromosomen, wie er im Mikrokerntest nachgewiesen wird, einen irreparablen genetischen Schaden dar, der entweder auf Chromosomenbrüche zurückzuführen ist (clastogene Wir-

Tabelle 2 Charakterisierung der DNA-Fragmentierung (verändert nach Schnurstein 2001)

\begin{tabular}{ll}
\hline Tail-Moment & Grad der DNA-Schädigung \\
\hline $0,1-1,0$ & Kontrolle \\
$1,0-1,9$ & Nachweisgrenze für gentoxische Effekte \\
$2,0-5,9$ & Leichte DNA-Schädigung \\
$6,0-15,0$ & Deutliche DNA-Schädigung \\
$15,0-45,0$ & Starke DNA-Schädigung \\
$>45,0$ & Sehr starke DNA-Schädigung \\
\hline
\end{tabular}


kung; vgl. z. B. Amdao et al. 2006) oder aber auf Störungen der Funktion des Spindelapparats (aneugene Wirkung; vgl. z. B. Digue et al. 1999) beruht. Im Vergleich mit Barben (Barbus barbus) aus der Donau (Böttcher 2005) weisen sowohl Rotaugen als auch Gründlinge aus dem Unteren Neckar durchgehend geringere Mikrokernraten auf (Abb. 16); ob dies jedoch auf artspezifische oder ortsspezifische Unterschiede zurückzuführen ist, kann derzeit nicht geklärt werden (vgl. Grisolia und Cordeiro 2000). Freilandstudien an Barben (Barbus plebejus) und Moskitofischen (Gambusia spec.) von unterschiedlich kontaminierten Flüssen in Italien (Minissi et al. 1996; Russo et al. 1999, 2004) belegen, dass Mikrokernraten zwischen 0,15 und 0,32\%o gegenüber Kontrollwerten von $0,05 \%$ bereits sehr gut mit dem Belastungsgrad der Gewässer in Einklang gebracht werden können. Auch eine Exposition von Tilapien (Oreochromis niloticus) gegenüber stark kontaminierten Standorten in Brasilien (Tiete River) führt zu einer Zunahme von Mikrokernraten in Erythrocyten von $1 \%$ bei Kontrollfischen auf Raten von bis zu $6 \%$ (Rocha et al. 2009). Zahlreiche weitere Studien belegen die grundsätzliche Eignung des Mikrokerntests für die Identifikation gentoxischer und mutagener Effekte in Fischen im Freiland (Al-Sabti und Harding 1990; Al-Sabti und Metcalfe 1995; Balch et al. 1995; Carrasco et al. 1990; Das und Nanda 1986; De Flora et al. 1993; Devaux et al. 1998; Hose et al. 1987; Hughes und Hebert 1991; Maccubin et al. 1991; Metcalfe et al. 1990).

Grundsätzlich ist festzuhalten, dass die Untersuchung gentoxischer und mutagener Effekte wie auch anderer toxischer Effekte mit Hilfe von Sedimentextrakten ein „Worst-

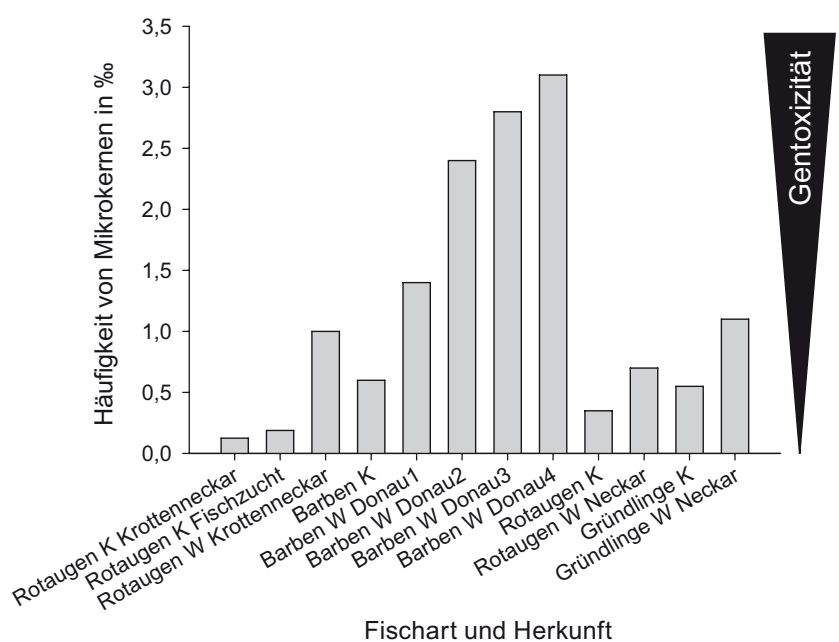

Abb. 16 Mikrokernrate im Erythrocyten von Rotaugen (Rutilus rutilus) aus dem „Krottenneckar“, Barben (Barbus barbus) aus der Donau (Böttcher 2005; Standorte 1 bis 4) und Rotaugen sowie Gründlingen (Gobio gobio) aus dem Neckar (Schnurstein 2000); $K$ Kontrollgruppe, $W$ Wildfänge
Case-Szenario“ darstellen, d.h., es wird das maximale Schädigungspotenzial erfasst, ohne die tatsächliche Bioverfügbarkeit zu berücksichtigen. Dennoch konnte generell bereits in mehreren Studien eine Korrelation zwischen der Induktion gentoxischer Effekte und populationsrelevanten Veränderungen gezeigt werden (Chen und White 2004; Diekmann et al. 2004a,b; White et al. 1999). Ein schlüssiger Beweis der ökologischen Relevanz mutagener und vor allem gentoxischer Effekte steht jedoch aus, solange keine überzeugenden Studien zur Gentoxizität und Mutagenität in Reproduktionsorganen vorliegen.

\section{Schlussfolgerungen}

Trotz einer deutlichen Verbesserung der allgemeinen Gewässergüte zeigen zahlreiche mitteleuropäische und nordamerikanische Gewässer keine entsprechende Erholung der Fischpopulationen. Ökotoxikologische Untersuchungen liefern für zahlreiche Endpunkte Befunde, die neben anderen Faktoren als Gründe für die Erklärung der beobachteten Artenfehlbeträge herangezogen werden können.

Untersuchungen zur biologischen Wirksamkeit von Schadstoffeinträgen sind keinesfalls durch chemisch-analytische Methoden zu ersetzen. Mit Hilfe der biologischen Tests ist es zwar nicht möglich, die chemische Natur der Substanzen zu identifizieren, die die Effekte auslösen; die Biotests belegen jedoch, dass auch der Neckar wie andere Flusssysteme nach wie vor anthropogenen Belastungen ausgesetzt sind, sei es durch unvollständige Klärung von Abwässern (Ahel et al. 1996; Garcia-Reyero et al. 2001; Hollert et al. 2005; Lee et al. 2004; Murk et al. 2002), durch atmosphärische Deposition (Erdinger et al. 2005) oder durch Oberflächenabfluss von landwirtschaftlichen Nutzflächen (Pedersen et al. 2003, Schulz und Liess 1999) oder versiegelten Siedlungsflächen (Fries und Puttmann 2003; Maltby et al. 1995). Dabei dürfte neben typischen prioritären Schadstoffen eine zunehmende Anzahl weiterer Substanzen (z.B. endokrin und gentoxisch wirksame Verbindungen) eine Rolle spielen (Faller et al. 2003; Vos et al. 2000; White et al. 1998).

Die in den letzten Jahrzehnten erreichte Verbesserung der Wasserqualität darf also nicht als Argument für ein Aussetzen regelmäßiger biologischer Untersuchungen („Umweltbeobachtung“) herangezogen werden. Für eine angemessene Bewertung subletaler und/oder spezifischer biologischer Effekte in Organismen (z.B. gentoxische oder endokrine Wirkungen) ist deren Relevanz für Veränderungen der Strukturen von Populationen allerdings dringend zu klären. Zur Identifikation der chemischen Grundlage für die beobachteten biologischen Wirkungen bieten sich integrierte Ansätze wie etwa Effekt-dirigierte Analysen an (Brack et al. 1999, 2005). 


\section{Literatur}

Ahlf W, Hollert H, Neumann-Hensel H, Ricking M (2002) A guidance for the assessment and evaluation of sediment quality: A German approach based on ecotoxicological and chemical measurements. J Soils Sed 2:37-42

Al-Sabti K, Harding J (1990) Micronucleus test in fish for monitoring the genotoxic effects of industrial waste products in the Baltic Sea, Sweden. Comp Biochem Physiol 97C:179-182

Al-Sabti K, Metcalfe CD (1995) Fish micronuclei for assessing genotoxicity in water. Mutat Res 343:121-135

Ayllon F, Garcia-Vazquez E (2000) Induction of micronuclei and other nuclear abnormalities in European minnow Phoxinus phoxinus and mollie Poecilia latipinna: an assessment of the fish micronucleus test. Mutat Res 467:177-186

Balch GC, Metcalfe CD, Huestis SY (1995) Identification of Potential Fish Carcinogens in Sediment from Hamilton Harbour, Ontario, Canada. Environ Toxicol Chem 14:79-91

Belpaeme K, Cooreman K, Kirsch-Volders M (1998) Development and validation of the in vivo alkaline comet assay for detecting genomic damage in marine flatfish. Mutat Res 415:167-184

Borenfreund E, Puerner JA (1985) Toxicity determined in vitro by morphological alterations and neutral red absorption. Toxicol Lett 24:119-124

Böttcher M 2005: Untersuchung zur Gentoxizität anhand von Sedimenten und Fischen der Donau. Univ. Heidelberg, 105 pp

Brack W, Altenburger R, Ensenbach U, Möder M, Segner H, Schüürmann G (1999) Bioassay-directed identification of organic toxicants in river sediment in the industrial region of Bitterfeld (Germany)-a contribution to hazard assessment. Arch Environ Contam Toxicol 37:164-174

Brack W, Schirmer K, Erdinger L, Hollert H (2005) Effect-directed analysis of mutagens and ethoxyresorufin-o-deethylase inducers in aquatic sediments. Environ Toxicol Chem 24:2445-2458

Braunbeck T, Gorgas K, Storch V, Völkl A (1987) Ultrastructure of hepatocytes in golden ide (Leuciscus idus melanotus L.; Cyprinidae: Teleostei) during thermal adaptation. Anat Embryol 175:303-313

Braunbeck T (1989) Cytopathologische Veränderungen in der Fischleber durch Umweltchemikalien-Beiträge zur Ökotoxikologie. PhD Thesis, Univ. of Heidelberg, Heidelberg, 329 pp

Braunbeck T, Storch V, Nagel R (1989) Sex-specific reaction of liver ultrastructure in zebrafish (Brachydanio rerio) after prolonged sublethal exposure to 4-nitrophenol. Aquat Toxicol 14:185-202

Braunbeck T, Storch V, Bresch H (1990) Species-specific reaction of liver ultrastructure of zebrafish (Brachydanio rerio) and trout (Salmo gairdneri) after prolonged exposure to 4-chloroaniline. Arch Environ Contam Toxicol 19:405-418

Braunbeck T (1992) Umweltcytologie-zelluläre Reaktionen zum Nachweis einer Schadstoffbelastung von Organismen. Ruperto Carola 85:61-85

Braunbeck T, Völkl A (1993) Toxicant-induced cytological alterations in fish liver as biomarkers of environmental pollution? A casestudy on hepatocellular effects of dinitro-o-cresol in golden ide (Leuciscus idus melanotus). In: Braunbeck T, Hanke W, Segner H (Editors), Fish ecotoxicology and ecophysiology. VCH, Weinheim, pp 55-80

Braunbeck T (1994) Strukturelle und funktionelle Veränderungen in Hepatocyten von Fischen als Biomarker für die Belastung durch Umweltchemikalien. Habilitation Thesis, Univ. Heidelberg, Heidelberg, $213 \mathrm{pp}$

Braunbeck T (1995) Zelltests in der Ökotoxikologie-Cytotoxizitätstests mit Zellkulturen aus Fischen als Alternative und Ergänzung zu konventionellen Fischtests. Veröff PAÖ 11, 204 pp

Braunbeck T (1996) Toxikologische und ökotoxikologische Untersuchung und Bewertung verschiedener Kompartimente in Fliess- gewässern mit Hilfe von Zellkulturen aus Fischen - ein Update. 3. Statuskolloquium des Projektes „Angewandte Ökologie", Ettlingen

Braunbeck T (1998) Cytological alterations in fish hepatocytes-in vivo and in vitro biomarkers of environmental contamination. In: Braunbeck T, Hinton DE, Streit B (Editors), Fish ecotoxicology. Experientia, Suppl. Ser. Birkhäuser, Basel, pp. 61-140

Braunbeck T, Appelbaum S (1999) Ultrastructural alterations in the liver and intestine of carp (Cyprinus carpio) induced by ultra-low peroral doses of endosulfan. Dis Aquat Org 36:183-200

Braunbeck T, Deventer K, Eisenträger A, Glück U, Grummt T, Gminski R, Hansen PD, Kramer M, Mersch-Sundermann V, Miltenburger HG, Reifferscheid G, Renberg P, Schnurstein A, Waldmann P, Wittekindt E, Zipperle J (2003) Gentoxizitätsprüfung im aquatischen Bereich B Möglichkeiten und Perspektiven. Vom Wasser 137:137-232

Braunbeck T, Böttcher M, Hollert H, Kosmehl T, Lammer E, Leist E, Rudolf M, Seitz N (2005) Towards an alternative for the acute fish $\mathrm{LC}_{50}$ test in chemical assessment: The fish embryo toxicity test goes multi-species-an update. ALTEX 22:87-102

Brauns, A (2008) Ökotoxikologische Untersuchungen zur Belastung von Sedimenten vom Unteren Neckar. Staatsexemanesarbeit, Univ. Heidelberg, $58 \mathrm{pp}$

Burkhardt-Holm P, Segner H (2002) Decline of fish catch in Switzerland. Aquatic Sci 64:36-54

Burkhardt-Holm P, Giger W, Güttinger H, Ochsenbein U, Peter A, Scheurer K, Segner H, Staub E, Suter MJ (2005) Where have all the fish gone? The reasons why fish catches in Swiss rivers are declining. Environ Sci Technol 39:441A-447A

Burkhardt-Holm P (2008) Decline of brown trout (Salmo trutta) in Switzerland-how to assess potential causes in a multi-factorial cause-effect relationship. Mar Environ Res 66, 181-182

Carrasco KR, Tilbury KL, Myers MS (1990) Assessment of the piscine micronucleus test as an in situ biological indicator of chemical contaminant effects. Can J Fish Aquat Sci. 47:2123-2136

Castaño A, Bols N, Braunbeck T, Dierichx P, Halder M, Isomaa B, Kawahara K, Lee LEJ, Mothersil P, Repeto G, Sintes JR, Rufli H, Smith R, Wood C, Segner H (2003) The use of fish cells in ecotoxicology-the report and recommendations of ECVAM workshop 47. ATLA 31:317-351

Castaño A, Gómez-Lechón MJ (2005) Comparison of basal cytotoxicity data between mammalian and fish cell lines. Toxicol in vitro 19:695-705

Chen G, White PA (2004) The mutagenic hazards of aquatic sediments: a review. Mutat Res 567:151-225

Cook PM, Robbins JA, Endicott DD, Lodge KB, Guiney PD, Walker MK, Zabel EW, Peterson RE (2003) Effects of aryl hydrocarbon receptor-mediated early life stage toxicity on lake trout populations in Lake Ontario during the 20th century. Environ Sci Technol 37, 3864-3877

Cotelle S, Ferard JF (1999) Comet assay in genetic ecotoxicology: a review. Environ Mol Mutagen 34:246-255

Das RK, Nanda NK (1986) Induction of micronuclei in peripheral erythrocytes of fish Heteropneustes fossilis by mitomycin $\mathrm{C}$ and paper mill effluent. Mutat Res 175:67-71

Davoren M, Shúilleabháin SN, O'Halloran J, Hartl MG, Sheehan D, O'Brien NM, van Pelt FN, Mothersill C (2005) A test battery approach for the ecotoxicological evaluation of estuarine sediments. Ecotoxicology 14:741-755

De Flora S, Vigano L, D'Agostini F, Camoirano A, Bagnasco M, Bennicelli C, Melodia F, Arillo A (1993) Multiple genotoxicity biomarkers in fish exposed in situ to polluted river water. Mutat Res 319:167-177

de Lafontaine Y, Gilbert NL, Dumouchel F, Brochu C, Moore S, Pelletier E, Dumont P, Branchaud A (2002) Is chemical contamination responsible for the decline of the copper redhorse (Moxostoma 
hubbsi), an endangered fish species, in Canada? Sci Total Environ 21:25-44

Devaux A, Flammarion P, Bernardon V, Garric J, Monod G (1998) Monitoring of the chemical pollution of the River Rhone through measurement of DNA damage and cytochrome P4501A induction in chub(Leuciscus cephalus). Mar Environ Res 46:257-262

Digue L, Orsière T, De Méo M, Mattéi MG, Depetris D, Duffaud F, Favre R, Botta A (1999) Evaluation of the genotoxic activity of paclitaxel by the in vitro micronucleus test in combination with fluorescent in situ hybridization of a DNA centromeric probe and the alkaline single cell gel electrophoresis technique (comet assay) in human T-lymphocytes. Environ Mol Mutagen 34:269-278

Diekmann M, Hultsch V, Nagel R (2004a) On the relevance of genotoxicity for fish populations I: effects of a model genotoxicant on zebrafish (Danio rerio) in a complete life-cycle test. Aquat Tox 68:13-26

Diekmann M, Waldmann P, Schnurstein A, Grummt T, Braunbeck T, Nagel R (2004b) On the relevance of genotoxicity for fish populations II: Genotoxic effects in zebrafish (Danio rerio) exposed to 4-nitroquinoline-1-oxide in a complete life-cycle test. Aquat Toxicol 68:27-37

Duerr M, Hollert H, Braunbeck T, Erdinger L, Sonntag H-G (1996) Untersuchungen zur Cyto- und Genotoxizität verschiedener Kompartimente des Neckars bei Hochwasser. Hyg Med 21:16

Escher BI, Bramaz N, Eggen RI, Richter M (2005) In vitro assessment of modes of toxic action of pharmaceuticals in aquatic life. Environ Sci Technol 39:3090-3100

Fairbairn DW, Olive PL, O'Neill KL (1995) The comet assay: a comprehensive review. Mutat Res 339:37-59

Faller P, Kobler B, Peter A, Sumpter JP, Burkhardt-Holm P (2003) Stress status of gudgeon (Gobio gobio) from rivers in Switzerland with and without input of sewage treatment plant effluent. Environ Toxicol Chem 22:2063-2072

Förstner U, Müller G (1974) Schwermetalle in Flüssen und Seen. Springer, Heidelberg

Grisolia CK, Cordeiro CMT (2000) Variability in micronucleus induction with different mutagens applied to several species of fish. Genet Mol Biol 23:235-239

Günther A (1853) Die Fische des Neckars. Jahreshefte des Vereins für vaterländische Naturkunde in Baden-Württemberg 9:225-360

Hinton DE, Segner H, Braunbeck T (2001) Toxic responses of the liver. In: Schlenk D, Benson WH (Editors), Target organ toxicity in marine and freshwater teleosts. Taylor \& Francis, London, New York, pp. 224-268

Hollert H, Braunbeck T (1997) Ökotoxikologie in vitro - Gefährdungspotential in Wasser, Sediment und Schwebstoffen. Veröff PAÖ 21, 189 pp

Hollert H, Dürr M, Dörr I, Erdinger L, Braunbeck T (1996) Toxikologische und ökotoxikologische Untersuchung und Bewertung der Kompartimente in Fließgewässern mit Hilfe von Zellkulturen aus Fischen. Veröff PAÖ 16:469-488

Hollert H, Dürr M, Erdinger L, Braunbeck T (2000a) Cytotoxicity of settling particulate matter and sediments of the Neckar river (Germany) during a winter flood. Environ Toxicol Chem 19:528-534

Hollert H, Karaus U, Braunbeck T (2000b) Ökotoxikologische Belastung von Neckarsedimenten. Zwischenbericht an die Bundesanstalt für Gewässerkunde, $65 \mathrm{p}$

Hollert H, Dürr M, Olsman H, Halldin K, van Bavel B, Brack W, Tysklind M, Engwall M, Braunbeck T (2002a) Biological and chemical determination of dioxin-like compounds in sediments by means of a sediment triad approach in the catchment area of the river Neckar. Ecotoxicology 11, 323-336

Hollert H, Heise S, Pudenz S, Brüggemann R, Ahlf W, Braunbeck T (2002b) Application of a sediment quality triad and different statistical approaches (Hasse diagrams and fuzzy logic) for the comparative evaluation of small streams. Ecotoxicology 11:311-321
Hollert H, Keiter S, König N, Rudolf M, Ulrich M, Braunbeck T (2003) A new sediment contact assay to assess particle-bound pollutants using zebrafish (Danio rerio) embryos. J Soils Sed 3:197-207

Hollert H, Dürr M, Holtey-Weber R, Islinger M, Brack W, Färber H, Erdinger L, Braunbeck T (2005) Endocrine disruption of water and sediment extracts in a non-radioactive dot blot/RNAse protection-assay using isolated hepatocytes of rainbow trout. Environ Sci Pollut Res Int 12:347-360

Hose JE, Cross JN, Smith SG, Diehl D (1987) Elevated circulating erythrocyte micronuclei in fishes from contaminated sites off southern California. Mar Environ Res 22:167-176

Hughes JB, Hebert AT (1991) Erythrocyte micronuclei in winter flounder (Pseudopleuronectes americanus): results of field surveys during 1980-1988 from Virginia to Nova Scotia and in long Island Sound. Arch Environ Contam Toxicol 20:474-479

Ingersoll CG, Dillon T, Biddinger GR (1997) Ecological risk assessment of contaminated sediments. SETAC-Press

Keiter S, Rastall A, Kosmehl T, Wurm K, Erdinger L, Braunbeck T, Hollert H (2006) Ecotoxicological assessment of sediment, suspended matter and water samples in the upper Danube River. A pilot study in search for the causes for the decline of fish catches. Environ Sci Pollut Res Int 13:308-319

Keiter S, Grund S, van Bavel B, Hagberg J, Engwall M, Kammann U, Klempt M, Manz W, Olsman H, Braunbeck T, Hollert H (2008) Activities and identification of aryl hydrocarbon receptor agonists in sediments from the Danube river. Anal Bioanal Chem 390:2009-2019

Kern U, Westrich B (1995) Sediment contamination b heavy metals in a lock-regulated section of the river Neckar. Mar Freshwater Res 46:101-106

Kobus H, Bürkle F (1996) Konkurrierende Ansprüche an ein Fließgewässer - das Beispiel Neckar. In: Lehn H, Steiner M, Mohr H (Editors), Wasser - Die elementare Ressource. Materialienband., Stuttgart, pp. 86-113

König N (2002) Der Zebrabärbling (Danio rerio) im Fischeitest und Comet-Assay. Diplomarbeit, Univ. Heidelberg, 63 pp

König N, Garke V, Kosmehl T, Glaß B, Golod A, Leist E, Wetterauer B, Johannsen H, Braunbeck T, Hollert H (2002) Der Zebrabärbling in Fischeitest und Comet-Assay-Embryotoxische Untersuchungen von Rheinsedimenten. Bericht an die Bundesanstalt für Gewässerkunde

Kosmehl T, Krebs F, Werner M, Erdinger L, Braunbeck T, Hollert $\mathrm{H}$ (2004) Comparative genotoxicity testing of Rhine river sediments extracts using the comet assay with permanent fish cell lines (RTG-2 and RTL-W1) and the Ames test. J Soils Sed 4:84-94

Kosmehl T, Hallare AV, Reifferscheid G, Manz W, Braunbeck T, Hollert H (2006) A novel contact assay for testing genotoxicity of chemicals and whole sediments in zebrafish embryos. Environ Toxicol Chem 25:2097-2106

Kosmehl T, Krebs F, Manz W, Braunbeck T, Hollert H (2007) Differentiation between bioavailable and total hazard potential of sediment-induced DNA fragmentation as measured by the comet assay with zebrafish embryos. J Soils Sed 7:377-387

Kosmehl T, Hallare AV, Braunbeck T, Hollert H (2008) DNA damage induced by genotoxicants in zebrafish (Danio rerio) embryos after contact exposure to freeze-dried sediment and sediment extracts from Laguna Lake (The Philippines) as measured by the comet assay. Mutat Res 650:1-14

Lammer E, Carr GJ, Wendler K, Rawlings JM, Belanger SE, Braunbeck T (2009) Is the fish embryo toxicity test (FET) with the zebrafish (Danio rerio) a potential alternative for the fish acute toxicity test? Comp Biochem Physiol 149C:196-209

Lauterborn R (1938) Der Rhein. Naturgeschichte eines deutschen Stromes. Zweite Hälfte: Die Zeit von 1800 bis 1930, Abteilung II: Der Oberrhein mit den Schwäbischen Neckarlanden. Kommissi- 
ons-Verlag der Buchhandlung August Lauterborn, Ludwigshafen, $439 \mathrm{pp}$

Lee LEJ, Clemons JH, Bechtel DG, Caldwell SJ, Han K, PasitschniakArts M, Mosser DD, Bols NC (1993) Development and characterization of a rainbow trout liver cell line expressing cytochrome p450-dependent monooxygenase activity. Cell Biol Toxicol 9:279-294

Lee YM, Oleszkiewicz JA, Cicek N, Londry K (2004) Endocrine disrupting compounds (EDC) in municipal wastewater treatment: A need for mass balance. Environ Technol 25:635-645

LfU-Baden-Württemberg (2002) Beschaffenheit der Fließgewässer. Jahresdatenkatalog 1972-2001 und aktueller Gütebericht 2001., Landesanstalt für Umweltschutz, Karlsruhe

Maccubin AE, Ersing N, Frank ME (1991) Mutagenicity of sediment from the Detroit River. J. Great Lakes Res. 17:314-321

Marthaler H, Pawlowski S (2005) Fische im Neckar. In: Brandis D, Hollert H, Storch V (Hrsg.) Artenvielfalt in Heidelberg, 2. Aufl. Selbstverlag Zoolog Inst Heidelberg, ISBN 3-00-016362-X

McKelvey-Martin VJ, Green MHL, Schmezer P, Pool-Zobel BL, De Méo MP, Collins A (1993) The single cell gel electrophoresis assay (comet assay) A European review. Mutat Res 288:47-63

Metcalfe CD, Balch GC, Cairns VW, Fitzsimons JD, Dunn BP (1990) Carcinogenic and genotoxic activity of extracts from contaminated sediments in western Lake Ontario. Sci Total Environ 94:125-141

Minissi S, Ciccotti E, Rizzoni M (1996) Micronucleus test in erythrocytes of Barbus plebejus (Teleostei, Pisces) from two natural environments: a bioassay for the in situ detection of mutagens in freshwater. Mutat Res 367:245-251

Ministerium für Ernährung LUB-W (1973) Wärmelastplan Neckar, Plochingen bis Mannheim., 3. Ministerium für Ernährung, Landwirtschaft und Umwelt Baden-Württemberg, Stuttgart

Mitchelmore CL, Chipman JK (1998) DNA strand breakage in aquatic organisms and the potential value of the comet assay in environmental monitoring. Mutat Res 399:135-147

Müller G, Yahaya A, Gentner P (1993) Die Schwermetallbelastung der Sedimente des Neckars und seiner Zuflüsse: Bestandsaufnahme 1990 und Vergleich mit früheren Untersuchungen. Heidelberger Geowiss Abh 69:1-91

Nagel R (2002) DarT: The embryo test with the zebrafish Danio rerio - a general model in ecotoxicology and toxicology. ALTEX 19:38-48

Navas JM, Babín M, Casado S, Fernández C, Tarazona JV (2006) The Prestige oil spill: a laboratory study about the toxicity of the watersoluble fraction of the fuel oil. Mar Environ Res 62(Suppl):S352S355

Nehls S, Segner H (2001) Detection of DNA damage in two cell lines from rainbow trout, RTG-2 and RTL-W1, using the comet assay. Environ Toxicol 16:321-329

Pinter I (1986) Auswirkung der Abwassersanierungsmaßnahmen auf den Gütezustand des Neckars. In: Müller G (Hrsg.), Neckar-Umwelt-Symposium 22-23, Heidelberg, pp. 64-70

Power EA, Chapman PM (1992) Assessing sediment quality. In: Burton GA (Editor), Sediment toxicity assessment. Lewis Publ., Boca Raton, pp. 1-18

Reifferscheid G, Ziemann C, Fieblinger D, Dill F, Gminski R, Grummt HJ, Hafner C, Hollert H, Kunz S, Rodrigo G, Stopper H, Selke D (2008) Measurement of genotoxicity in wastewater samples with the in vitro micronucleus test: results of a round-robin study in the context of standardization according to ISO. Mutat Res 649:15-27

Rey P, Ortlepp J, Küry D (2005) Wirbellose Neozoen am Hochrhein. Schriftenreihe Umwelt. Bundesamt für Umwelt, Wald und Landschaft (BUWAL), Bern, 90 pp

Rocha PS, Kosmehl T, Luvizotto GL, Böttcher M, Braunbeck T, Storch V, Hollert H (2009) Assessment of genotoxicity of sedi- ments from Tietê River basin (São Paulo, Brazil) combining the in vitro comet assay and the in situ micronucleus assay using fish blood cells. Ecotox Eviron Saf, accepted for publication

Russo C, Rocco L, Stingo V, Aprea G, Odierna G (1999) Cytogenetic analysis in specimens of Gambusia holbrooki (Cyprinodontiformes, Poecilidae) from the Sarno River. Ital J Zool 66:291-296

Russo C, Rocco L, Morescalchi MA, Stingo V (2004) Assesment of environmental stress by the micronucleus test and the Comet assay on the genome of teleost populations from two natural environments. Ecotox Environ Saf 57:168-174

Schaal H, Bürkle F (1993) Von Wasser- und Kulturbau zur Wasserwirtschaftsverwaltung, 200 Jahre Wasserwirtschaft im Südwesten Deutschlands. Ministerium für Umwelt Baden-Württemberg

Scheil V, Kienle C, Osterauer R, Gerhardt A, Köhler HR (2008) Effects of 3,4-dichloroaniline and diazinon on different biological organisation levels of zebrafish (Danio rerio) embryos and larvae. Ecotoxicology 18, DOI 10.1007/s10646-008-0291-0

Schmid W (1975) The micronucleus test. Mutat Res 31:9-15

Schnurstein A 2000: Untersuchungen zur Gentoxizität in Fischen und Fischzellen mit der Einzelzell-Gelelektrophorese (Comet Assay) - Möglichkeiten und Grenzen im Biomonitoring. Dissertation Thesis, Ruprecht-Karls-Universität Heidelberg, $196 \mathrm{pp}$

Schnurstein A, Braunbeck T (2001) Tail moment versus tail length application of an in vitro version of the comet assay in biomonitoring for genotoxicity in native surface waters using primary hepatocytes and gill cells from zebrafish (Danio rerio). Ecotox Environ Saf 49:197-196

Segner H, Braunbeck T (1988) Hepatocellular adaptation to extreme nutritional conditions in ide, Leuciscus idus melanotus L. (Cyprinidae). A morphofunctional analysis. Fish Physiol Biochem 5:79-97

Segner H, Braunbeck T (1990) Environmental adaptation of the cyprinid teleost Leuciscus idus melanotus: Changes in liver composition and structure during the winter season. J Exp Zool 255:171-185

Segner H, Lenz D (1993) Cytotoxicity assays with the rainbow trout $\mathrm{R} 1$ cell line. Toxic in vitro 7:537-540

Segner H, Braunbeck T (1998) Cellular response profile to chemical stress. In: Schüürmann G, Markert B (Editors), Ecotoxicology. Wiley and Spektrum Akadem. Verlag, New York and Heidelberg, pp. 521-569

Seitz N 2005: Der ökotoxikologische Zustand der oberen Donau-eine integrierte Bewertung auf der Grundlage des Makrozoobenthos und Sedimentkontakttests mit Danio rerio., Diplomarbeit, Univ. Heidelberg, $205 \mathrm{pp}$

Seitz N, Böttcher M, Keiter S, Kosmehl T, Manz W, Hollert H, Braunbeck T (2008) A novel statistical approach for the evaluation of comet assay data. Mutat Res 652:38-45

Singh NP, Tice RR, Stephens RE, Schneider EL (1991) A microgel electrophoresis technique for the direct quantification of DNA damage and repair in individual fibroblasts cultured on microscope slides. Mutat Res 252:289-296

Steidle H (2007) Integrierte Konzeption Neckareinzusgebiet (IKoNE). In: Fachdienst Naturschutz LfU, Messung und Naturschutz Baden-Württemberg (Editor), Der Neckar. Das Land und sein Fluss. Verlag Regionalkultur, Karlsruhe, pp. 243-272

Weiß E (2007) Das Binnenschiff als ökologische Transportalternative. Schifffahrt auf dem Neckar besitzt lange Geschichte und hat Zukunft. In: Fachdienst Naturschutz LfU, Messung und Naturschutz Baden-Württemberg (Editor), Der Neckar. Das Land und sein Fluss. Verlag Regionalkultur, Karlsruhe, pp 273-280

White PA, Rasmussen JB, Blaise C (1998) Genotoxic substances in St. Lawrence system 1: industrial genotoxins sorbed to particula- 
te matter in the St. Lawrence, St. Maurice, and Saguenay rivers, Canada. Environ Toxicol Chem 17:286-303

White PA, Robitaille S, Rasmussen JB (1999) Heritable reproductive effects of benzo[a]pyrene on the fathead minnow (Pimephales promelas). Environ Toxicol Chem 18:1843-1847

Wnuck H (2000) Wandel der Fischartengemeinschaft im mittleren Neckar-ein Beispiel für anthropogen bedingte Veränderungen der Ichthyozönosen in unseren Flüssen im 19. und 20. Jahrhundert. Verbands-Informationen des Verbands für Fischerei und Gewäs- serschutz in Baden-Württemberg. Verband für Fischerei und Gewässerschutz in Baden-Württemberg

Wurm K 2001: Untersuchung zum Rückgang des fischereilichen Ertrages in der Donau zwischen Sigmaringen und Erbach., Gewässerökologisches Labor, Tübingen

Zahn T, Arnold H, Braunbeck T (1996) Cytological and biochemical response of R1 cells and isolated hepatocytes from rainbow trout (Oncorhynchus mykiss) to subacute in vitro exposure to disulfoton. Exp Toxicol Pathol 48:47-64 